\title{
El sí mismo y su conocimiento en la Bhagavad Gītā: la tradición sacrificial interiorizada
}

\author{
Gabriel Martino
}

Martino, G. (2021). El sí mismo y su conocimiento en la Bhagavad Gītāa: la tradición sacrificial interiorizada. Revista de Filología y Lingüística de la Universidad de Costa Rica, 47(2), e47248. doi: https://doi.org/10.15517/rfl.v47i2.47248

\section{(9) $(1) \Theta \Theta$}

Doi: https://doi.org/10.15517/rfl.v47i2.47248

URL: https://revistas.ucr.ac.cr/index.php/filyling/index 
Revista de Filología y Lingüística de la Universidad de Costa Rica

ISSN: 0377-628X

ISSN: 2215-2628

filyling@gmail.com

Universidad de Costa Rica

Costa Rica

\section{El sí mismo y su conocimiento en la Bhagavad Gītā: la tradición sacrificial interiorizada ${ }^{1}$}

Martino, Gabriel

El sí mismo y su conocimiento en la Bhagavad Gītā: la tradición sacrificial interiorizada ${ }^{1}$

Revista de Filología y Lingüística de la Universidad de Costa Rica, vol. 47, núm. 2, e47248, 2021

Universidad de Costa Rica, Costa Rica

Disponible en: https://www.redalyc.org/articulo.oa?id=33266553017

DOI: https://doi.org/10.15517/rfl.v47i2.47248

\section{(c) (1) $\Theta(9$}

Esta obra está bajo una Licencia Creative Commons Atribución-NoComercial-SinDerivar 3.0 Internacional. 


\section{El sí mismo y su conocimiento en la Bhagavad Gìtā: la tradición sacrificial interiorizada $^{1}$}

\section{The Self and its Knowledge in the Bhagavad Gìtä: The Sacrificial Tradition Internalized}

\section{Gabriel Martino}

Consejo Nacional de Investigaciones Cientificas y Técnicas de Argentina (CONICET), Universidad de Buenos Aires,

Buenos Aires, Argentina

gabriel.filosofía@hotmail.com

(iD https://orcid.org/0000-0003-2454-2026

\author{
DOI: https://doi.org/10.15517/rfl.v47i2.47248 \\ Redalyc: https://www.redalyc.org/articulo.oa? \\ $\mathrm{id}=33266553017$
}

Recepción: 24 Agosto 2020

Aprobación: 20 Octubre 2020

\section{Resumen:}

En el presente trabajo ofrecemos un análisis de la concepción del sí mismo y de su conocimiento en la Bhagavad Gìtā, y de la relación que estas nociones tienen con la reinterpretación del sacrificio védico presente en el tratado. Para llevar a cabo tal análisis, nos fundamos sobre la hipótesis de la composición estratificada del texto, propia de los estudios histórico-críticos, y centramos nuestro examen en el denominado estrato upanișadico. Nuestra metodología recurre al análisis del texto en su lengua original, el sánscrito, e interpretamos los pasajes examinados tomando en cuenta el carácter intertextual de la obra. Nuestras conclusiones procuran no solo esclarecer los conceptos analizados sino también mostrar que el estrato upanișadico de la Bhagavad Gìtā habría evidenciado una concepción monista de la realidad propia del sāṃkhya pre-clásico.

Palabras Clave: sí mismo, conocimiento de sí, interiorización del sacrificio, sāmkhya, monismo.

\section{ABSTRACT:}

In the present paper, we offer an analysis of the conceptions of the self and its knowledge in the Bhagavad Gitata, and of their relation to the interiorization of vedic sacrifice. In order to carry out this analysis, we take as our starting point the hypothesis of the stratified composition of the text, proposed by the historical-critical studies of the Bhagavad Gitä, and focus our exam on the upanișadic stratum. Our methodology involves the analysis of the text in its original language, Sanskrit, and its interpretation taking into consideration the intertextual character of the treatise. Our conclusions seek to elucidate the concepts analyzed and we also show that the upanișadic stratum of the Bhagavad Gitä would have evinced a monistic conception of reality characteristic of pre-classical sāṃkhya.

KEYWORDS: self, self-knowledge, interiorization of sacrifice, sāmkhya, monism.

\section{INTRODUCCIÓN}

En el presente trabajo, nos proponemos examinar la concepción del sí mismo y su relación con la concepción del sacrificio en la Bhagavad Gìtā. Buscamos, más específicamente, poner de manifiesto el procedimiento mediante el cual este texto clásico de la India articula su noción del sí mismo y de su conocimiento recurriendo a una reinterpretación de la práctica védico-brahmánica del sacrificio. Para llevar esto a cabo, también examinamos la concepción del sí mismo a partir de una lectura estratificada del texto y acotándonos a lo que se denomina el estrato upanisadico.

Tal como procuramos mostrar en nuestro análisis, la Bhagavad Gìtā abre un espacio en la interioridad del ser humano donde coloca al yo verdadero. Tal espacio interior no es, sin embargo, un sitio físico localizable, aunque sí es diferenciado de un ente espacial y físico: el cuerpo (deha). Se trata, más bien, de un espacio simbólico, un sitio en el que convergen ciertos significados que operan constituyendo aquello en lo que consiste ser un ser humano, aquello que da cuenta de lo que el sí mismo es. Por otra parte, la Bhagavad Gïtā 
nos permite apreciar que los símbolos utilizados para dar sentido al sí mismo, y la interioridad de aquellos, son el resultado de un proceso de reflexión en torno de ciertos textos previos y de performances discursivas también preexistentes. Las prácticas y textos aludidos, tras ser sometidos a un procedimiento exegético, son concebidos como aludiendo veladamente al sí mismo interior. Pero este, dado que no puede ser percibido mediante los sentidos, posee un carácter oculto que trae aparejada la necesidad de un desocultamiento. Así pues, en nuestro trabajo procuramos poner de manifiesto que en la Bhagavad Gìtā se ofrece un desciframiento del sí mismo interior mediante la (re)interpretación de la acción sacrificial. En el marco de este reinterpretar el sacrificio, el sí mismo es configurado, lo que permite al ser humano, a su vez, experimentar su tradición en una suerte de círculo hermenéutico, bajo una perspectiva renovada, liberadora e interiorizada.

En una primera sección del trabajo, brindamos una breve presentación de la correspondencia entre la concepción del hombre y el sacrificio en el pensamiento védico antiguo ${ }^{2}$. En un segundo apartado, discutimos las concepciones del sacrificio, del hombre y del conocimiento de sí en la Bhagavad Gitā y mostramos en qué medida se trata de nociones mutuamente solidarias que implican un procedimiento de alegorización e interiorización. En este segundo apartado, la discusión se acota a lo que los especialistas han reconocido como el estrato upanisadico del texto. Nuestra lectura, por tanto, se fundamenta sobre las hipótesis de la composición estratificada de la Bhagavad Gìtā e intenta arribar a conclusiones que atañen a la concepción del sí mismo en un estrato textual específico.

\section{ALgunAS CORRESPONDENCIAS ENTRE PURUȘA Y SACRIFICIO EN EL PENSAMIENTO VÉDICO ANTIGUO}

En el pensamiento de la India perteneciente a la tradición védica es posible encontrar una relación entre el hombre (puru $\mathbf{S}$ a) y el sacrificio (yajña) atestiguada en los textos más antiguos. Es bien conocido el himno a puru $\mathbf{S}$ a o puru $\mathbf{S}$ asüktam del $\mathbf{R} g$ Veda (X 90) en el que se describe el sacrificio ritual del puru $\mathbf{S} a$ u hombre cósmico primordial ${ }^{3}$. Se afirma que su grandeza es tal que una cuarta parte suya comprende a todos los seres, mientras que las otras tres cuartas partes están en el cielo y comprenden lo inmortal. Los dioses, los sadhya y los $\underset{r s}{i}$ sacrificaron al puru $\mathbf{S}$ a y a partir de él nacieron los distintos aspectos del Veda: las estrofas ( $\mathrm{r} c$ ), las melodías (sāman), las fórmulas litúrgicas o sacrificiales (yajus) y los versos (chandas). De su boca también surgió el brahmán; de sus brazos, el guerrero; de sus muslos, el vai 's ya, y de sus pies, el 's $\bar{u} d r a$. Los dioses Indra y Agni nacieron de su boca; de su aliento, Vayu; de su mente, la luna, y de su ojo, el sol. El espacio, el cielo, la tierra y las regiones del cosmos también surgieron a partir de él gracias al sacrificio ${ }^{4}$.

La Chāndogya Upani s ad contiene la llamativa afirmación: puru s o vāva yajña hạ "El hombre (es), ciertamente, el sacrificio" 5 . En ese texto se establecen una serie de correspondencias entre las etapas de la vida del hombre y las fases del ritual. La cronología de la vida del hombre queda estructurada a partir de las diferentes fases del sacrificio, y, si en alguna de las etapas de su vida el hombre sufriera algún deterioro en su salud, esta será restablecida mediante la afirmación de la identidad entre el hombre y el sacrificio. Así, si la enfermedad se sufre durante los primeros veinticuatro años de su vida, el joven debe decir lo siguiente: "Oh Vasu, que esta libación mía de la mañana sea una con la libación del mediodía. Que yo, un sacrificio, no me pierda en medio de los Vasu" ${ }^{6}$. De este modo, mediante la afirmación de la correspondencia entre su vida y el sacrificio, y mediante la realización de los sacrificios, el hombre garantiza que su vida sea completa tal como los sacrificios deben ser completos. Las libaciones de la mañana, del mediodía y de la tarde se ofrecen, respectivamente, con el metro gāyatrī, tri ș $u b h$ y jagati ${ }^{7}$. Estas clases de metro tienen veinticuatro, cuarenta y cuatro y cuarenta y ocho sílabas cada una. De esta manera, gracias a la correspondencia entre el hombre y el sacrificio, y a la efectiva realización de los sacrificios, el hombre podrá vivir las tres etapas completas de su vida que comprenden veinticuatro, cuarenta y cuatro y cuarenta y ocho años respectivamente: "quien conoce esto -afirma la Upani $\mathbf{S}$ ad-también vive ciento dieciséis años" ${ }^{8}$. 
Hay otro pasaje relevante en la Chāndogya Upani șad que nos gustaría comentar. En el Kha ṇd a diecisiete del Prapāthaka tercero, se expone la enseñanza que Ghora Āngirasa, una antigua y legendaria figura, habría enseñado a Kṛṣna. En esta enseñanza se traza un paralelismo entre otros elementos de la vida y del ritual. Allí leemos:

\begin{abstract}
Uno, en cuanto desea comer, desea beber y no se satisface eróticamente: esas son las consagraciones preparatorias de aquel. Luego, en cuanto come, bebe y disfruta de los placeres, está ocupado con los ritos preparatorios. Luego, en cuanto ríe, se divierte y tiene relaciones sexuales, por esto se ocupa con los sāstra y con las alabanzas. Luego, estas son las ofrendas de aquel: "la austeridad, la generosidad, la integridad, la no violencia y el discurso verdadero". A partir de esto, dicen: "exprimirá el soma. Se exprimió a sí mismo (como al soma)”. Eso es, ciertamente, la nueva regeneración de aquel. La ablución al final del ritual es ciertamente (como) la muerte ${ }^{9}$.
\end{abstract}

Estas líneas trazan un paralelismo entre elementos del ritual ( $d \bar{i} k \mathrm{~s} \bar{a}$ o "consagraciones preparatorias", dak s $i$ n $\bar{a}$ u "ofrendas", etc.) y aspectos de la conducta y de la vida moral del hombre. En este sentido, Radhakrishnan (1968) señala que las privaciones son igualadas a las iniciaciones; los disfrutes a los ritos y a las recitaciones; las virtudes a las ofrendas; la procreación a la regeneración; y la muerte al baño ritual final ${ }^{10}$ . Así pues, si tomamos en conjunto el himno a puru $\mathbf{s}$ a del $\mathrm{R}$ gveda y los pasajes discutidos de la Chāndogya Upani $\mathbf{s}$ ad, podemos apreciar la estrecha relación que el pensamiento védico, tanto en su etapa temprana como en un momento posterior, establece entre el puru $\mathrm{s}$ a y el sacrificio ${ }^{11}$.

De acuerdo con el himno del $\mathrm{R}$ gveda, puru $\mathrm{S}$ a parece preexistir al ritual sacrificial. Pero gracias a su sacrificio, el cielo y el mundo, el Veda, los dioses y los hombres con sus distinciones son producidos. Nótese, asimismo, que parte del Veda que surge del puru $\mathbf{s}$ a lo constituyen las formulas sacrificiales (yajus, de la raíz verbal $Y A J$, "venerar mediante el sacrificio"), un ingrediente fundamental del sacrificio védico. Luego, la Upani $\mathbf{s}$ ad establece explícitamente, por una parte, una identidad entre el hombre y el sacrificio y, por otra, una correspondencia del ritual con los distintos aspectos de la vida de un hombre: las etapas de la vida, la duración de la vida, la salud, su conducta social y moral e incluso su muerte. Tales correspondencias, por último, parecen implicar que para que estos distintos aspectos de la vida se desarrollen con normalidad y satisfactoriamente, la actividad ritual debe realizarse indefectiblemente, ya que la mutua implicación simbólica de ambos elementos deja entrever que ambas realidades se conciben como mutuamente dependientes en los hechos. La prescripción de la recitación ritual de ciertas afirmaciones específicas para restablecer la salud en las diferentes etapas de la vida pone de manifiesto tal concepción de mutua dependencia fáctica.

Ahora bien, nos interesa reparar brevemente en la introducción de la figura de Kụṣna en esta Upani s ad temprana, algo que ha llamado la atención a numerosos estudiosos, especialmente en relación con la figura protagonista de la Bhagavad Gìtā. Tal aparición ha hecho reflexionar a los estudiosos acerca de la historicidad de la figura de Krṣna y de la identidad o no de ambos Krṣna ${ }^{12}$. Para dar fuerza a la hipótesis que los identifica, además de la coincidencia tanto del nombre personal como del matronímico devakīputra, se han señalado similitudes entre las enseñanzas del ya aludido Ghora Āngirasa, y las que el mismo Kṛ̣na brinda a Arjuna en el célebre episodio del Mahābhārata ${ }^{13}$. Ya Barnett (1922, pp. 82-83) señala que la comparación de las funciones de la vida con las ceremonias de $d i k \mathbf{s} \bar{a}$ que encontramos en la Chändogya se asemeja a la enseñanza del karma-yoga expuesta en la Gìtā (véase $B h G$ IX 27); las virtudes morales enumeradas por Ghora son, junto con otras, las atribuidas por Kụsna al hombre que ha nacido para un destino divino (compárese con $B h G$ XVI 1-3). También indica la relación con la divinidad solar que ambas figuras manifiestan en los dos textos. Pero Ghora también le habría enseñado a Kụṣna que antes de morir uno debe refugiarse en la siguiente tríada: "eres el indestructible, el inconmovible, eres fortificado por los alientos" ${ }^{14}$. Esta instrucción es paralela con la afirmación que hallamos en la Bhagavad Gìtā según la cual quien en el momento de su muerte abandona su cuerpo pensando en Kṛṇa se convierte en él, puesto que "cualquier ser en que el hombre piense al abandonar su cuerpo en el momento de la muerte, a aquel ser él llega” ( $B h G$ VIII 5-6. Véase, asimismo, VIII 10). 
Como podemos apreciar, si aceptamos la hipótesis de la identidad de ambos Kṛsna, su figura parece estar asociada ya desde una etapa muy temprana con una peculiar visión del sacrificio. Tal concepción traza una correspondencia entre el ritual y la existencia del hombre, concebida como una actividad que abarca todas las fases de su vida y los aspectos de su comportamiento. Sin embargo, tal como aparece formulada en la Chändogya, esta correspondencia no se plantea en detrimento de la dimensión literal del ritual, sino que, por el contrario, parece formularse con la finalidad de garantizar su ejecución, dado que de ella depende el correcto desenvolvimiento de los distintos aspectos de la vida del hombre. Como intentamos mostrar a continuación, la Bhagavad Gìtā desarrolla esta vinculación entre el ritual y la vida humana pero le otorga un nuevo carácter motivado por una también novedosa finalidad.

\section{SACRIficio y sí Mismo EN LA Gī tā}

Si dirigimos nuestra atención a la Bhagavad Gìtā, vemos que allí también Kṛ̣na aparece ligado, en este caso como portavoz, a una enseñanza peculiar acerca del sacrificio. En ella se aprecia un acentuado desarrollo de la correspondencia antes mencionada entre el hombre y el ritual o sacrificio (yajña). Aunque la Bhagavad Gìtā habría atravesado un largo período de composición oral, su forma debe haberse consolidado en el último siglo antes de la era común. El texto tal como lo conocemos, pues, pertenece a un período posterior a la cultura védica, aunque posiblemente sea contemporánea con algunas Upani $\mathrm{S}$ ad medias, como la $\mathrm{S}$ vetā 's vatara, tratado con el que comparte muchos elementos doctrinales y formales ${ }^{15}$.

Como es sabido, la Bhagavad Gìtā pertenece al Mahäbhārata, Libro VI (Bhī s ma Parvan) capítulos 25-42, y dado que ha recibido una veneración particular desde una época bastante temprana, ocupa un lugar excepcional en la epopeya. Ha sido comentada como si se tratase de una obra independiente tanto en la Antigüedad como en la actualidad (Riviere, 1997, p. 20). En este tratado, se narran el célebre momento inicial de la gran batalla fratricida entre los Pāṇ̣ava y sus primos los Kaurava, y la negativa de Arjuna, héroe Pāṇ̣ava, a pelear contra sus familiares. En este contexto, se incluye una extensa exposición de carácter religioso y filosófico que constituye la exhortación que Kṛṣna le dirige a Arjuna para que se decida a pelear y cumpla, de ese modo, con su deber de guerrero.

\subsection{Elementos de la lectura estratificada}

Ahora bien, la Bhagavad Gìtā ha sido analizada por algunos estudiosos desde la perspectiva de la crítica textual y filológica, gracias a lo cual se propone identificar una porción del texto estrechamente ligado con el pensamiento volcado en las Upanisad medias y antiguas ${ }^{16}$. Mediante este abordaje, Ježić (2009), por ejemplo, ha distinguido cuatro categorías textuales en la Bhagavad Gìtā: (1) el episodio épico, (2a) el himno, (2b) el estrato upanisadico y (3) la síntesis bhakti. La primera categoría textual o el episodio épico sería el estrato más antiguo, incluye la descripción del marco narrativo y plantea el dilema de Arjuna. En ella, Krșna es representado como un amigo y cochero de Arjuna que expone una primera respuesta al dilema en términos del dharma o deber del guerrero $(k \mathbf{s} \text { atriya })^{17}$. El himno habría sido compuesto de manera independiente, por fuera del Mahābhārata, e insertado tardíamente de modo paralelo a la incorporación de la dimensión bhakti (devocional) al texto ${ }^{18}$. El estrato upanisádico contiene una estrecha relación textual y conceptual con la $\mathrm{Ka}$ t ha y la $\mathbf{S}$ vetā 's vatara Upani s ad, comprende principalmente los capítulos segundo a sexto y del décimo tercero al décimo octavo. En él, Kṛṇa es presentado como maestro o guru e incluye enseñanzas relativas al sā $m$ k khya, al yoga y al renunciamiento (sa m nyāsa). Por último, la síntesis bhakti o devocional presenta a Kụṣna como dios supremo, es de incorporación más reciente y comprende los capítulos VII a XII con alrededor de 22 interpolaciones en otros capítulos ${ }^{19}$. 
En lo que sigue, acotamos nuestro análisis de la concepción del sí mismo en la Gìtāa al estrato upanisádico. Dejamos de lado, pues, el llamado estrato épico, el correspondiente a la síntesis bhakti y el himno. Ježić afirma que esta sección es la que presenta la mayor cantidad de paralelismos con las Upani s ad, desde las perspectivas mítica, histórica, doctrinal y literal. Si bien a grandes rasgos comprende los capítulos II al VI y XIII al XVIII, Ježićc (2009) distingue las siguientes secciones:

I. BhG II a VI: Las Upani $\mathbf{s}$ ad (sā ṃ khya, yoga, sa m nyāsa)

(a) II, 11-30, 38, sección identificada como el primer estrato sā ṃ khya

(b) II, 39 y IV, 42, estrato sobre el yoga

(c) III, 9-16 y IV 23-34, digresiones sobre el sacrificio (yajña)

II. BhG XIII y XV: Las Upani $\mathbf{s} a d(k \underline{\mathrm{s}}$ etra-k $\mathbf{s}$ etrajña)

III. $B h G \mathrm{XVI}$ : Clasificaciones

IV. $B h G$ XIV, XVII y XVIII: Clasificaciones

V. BhG XVIII (41, 49, 54, 64-73): Conclusión

Ahora bien, de este estrato nos concentramos principalmente en dos secciones: I (c) y II, pues estas contienen las discusiones en torno al sacrificio y al sí mismo que más nos interesa examinar, aunque también tomamos en cuenta elementos discutidos en otras de las secciones listadas. Ya Barnett (1922), como comentamos anteriormente, había señalado el paralelismo que las enseñanzas de Kụṣna en la Bhagavad Gĩtā presentan con las que Ghora transmite a Kṛ̣na devakiputra en la Chāndogya Upani $\mathbf{s}$ ad, especialmente las correspondencias que establece entre la conducta y el sacrificio. Ježíc retoma este punto de vista y afirma que tales correspondencias nos remiten directamente al grupo (c) de estrofas sobre yajña aunque también al karmayoga enseñado en la Gìtā donde el término karman se utiliza, en un sentido general, para todas las actividades de la vida (no simplemente para los actos rituales), pero se aplica especialmente a aquellas actividades que constituyen el deber (dharma) propio. La concepción de la acción en la Bhagavad Gìtā merece, sin lugar a dudas, un análisis pormenorizado ${ }^{20}$. En el presente trabajo, no obstante, la abordamos solo tangencialmente y en función de nuestra discusión en torno a las nociones de sacrificio y de sí mismo. Discutamos, pues, las estrofas dedicadas al sacrificio en primer término y, luego, las de la sección II.

\subsection{Yajña en la Bhagavad Gītā}

Como es sabido, el sacrificio (yajña) es la característica sobresaliente de la cultura védica antigua. La enseñanza de Kṛ̣na en Bhagavad Gìtāa, sin embargo, presenta severas críticas a esta cultura con su énfasis en el ritual sacrificial. Los especialistas han señalado distintos motivos que habrían llevado a algunos círculos brahmánicos a proponer una renovación de su propia cultura y a revisar sus prioridades. Van Buitenen, por ejemplo, explica que el brahmanismo estaba atravesando una fase convulsionada en los últimos siglos antes de la era cristiana y que nuevas doctrinas estaban siendo aceptadas por los sectores más cultivados de la sociedad brahmánica. La doctrina de la reencarnación que se estaba difundiendo rápidamente se conjugaba con dificultad con el antiguo sistema ortodoxo que veía en los actos (rituales) la cura de todas las aflicciones, puesto que la nueva doctrina inculpaba justamente a los actos como responsables de las aflicciones. Un defecto crucial, sin embargo, aquejaba a los movimientos en surgimiento: carecían de una visión supramundana consistente que pudiera dar sustento, a la vez, a un orden social y mundano. Van Buitenen afirma que Kụsna logra zanjar esta dificultad: es un héroe de la propia tradición brahmánica, un dios poderoso y a la vez bondadoso, garante de la estabilidad social, sostenedor del dharma de clase y de los estadios de la vida, posee la respuesta a la doctrina de la reencarnación y adapta en términos aceptables para la ortodoxia el ideal de renunciamiento propio de las tradiciones heterodoxas (1981, pp. 12-13). 
Citemos, en primer término, unas estrofas que ejemplifican la crítica de Kụṣ̣a a la ortodoxia brahmánica.

Los insensatos que se deleitan en las palabras de los Veda, oh Partha, de los cuales su naturaleza es el deseo y su finalidad el cielo, proclaman estas que son palabras floridas diciendo: "no hay otra cosa". Estas proporcionan el (re)nacimiento como fruto de los actos, son abundantes en diferentes acciones rituales y relativas al camino del poderío y del disfrute.

El intelecto de naturaleza resuelta de los que están apegados al poderío y al disfrute, cuyas mentes fueron capturadas por estas (palabras), no está destinado para la concentración ${ }^{21}$.

Como podemos apreciar, Kụṣna no acepta sin más la actividad ritual védica. La amplia gama de acciones sacrificiales puede estar motivada por el deseo de poder y de disfrutes, y este apego trae como resultado el renacimiento. Tal conducta es la que Kụsnna condena. En las estrofas que siguen a las citadas, Kṛnna recurre a nociones del sā m khya para explicar que un modo semejante de conducirse se encuentra íntimamente implicado con los gu n $a$, las cualidades de prak $\mathrm{r}$ ti que son ajenas al sí mismo verdadero e interior: el ätman o puru $\mathbf{s} a$. Por este motivo, Krṣna afirma: "los Vedas tienen por objeto lo que posee tres gu na. Oh Arjuna, vuélvete libre de los tres $g u$ n $a^{\prime 22}$.

Ahora bien, debemos preguntarnos cómo es posible que Kṛnna censure, por una parte, a los Veda y al enorme conjunto de acciones sacrificiales que estos prescriben y regulan, pero se mantenga, a su vez, dentro del marco aceptable de la ortodoxia brahmánica. Kṛsna logra, en efecto, introducir su instrucción entre dos posiciones antagónicas: la del sacrificio motivado por el deseo y la de la renuncia corrompedora del orden ortodoxo. Esta segunda posición se expresa con claridad en el primer grupo de estrofas que pertenece a la sección I (c) distinguida por Ježić, los 's loka 9 a 16 del tercer capítulo. Allí, Kṛsṇa afirma que aquellos que consumen los restos del sacrificio se liberan de los males, mientras que quienes preparan sus alimentos para sí mismos son malvados y disfrutan su propia maldad (III 13) ${ }^{23}$. En esta sección, incluso se brinda una caracterización del Veda que se contrapone en cierta medida con las estrofas II 42-46 antes citadas.

Los seres surgen a partir del alimento, el origen de los alimentos es a partir de la lluvia, la lluvia surge a partir del sacrificio, el sacrificio tiene su origen en la acción.

Sabe que la acción tiene su origen en Brahman, y que el surgimiento de Brahman es a partir de lo imperecedero. Por eso Brahman, difundido por todas las cosas, está eternamente establecido en el sacrificio ${ }^{24}$.

Estas estrofas ponen de manifiesto el sentido cósmico que el ritual sacrificial poseía en la cultura (post)védica. Como afirma Tola en su comentario a estas estrofas, "la realización de los sacrificios prescritos por la tradición religiosa es la que asegura la continuación del proceso cósmico, como la aparición del día y de la noche, la llegada de las lluvias, etc." (Tola, 2000, p. 62, nota 22). En la primera de las estrofas, de hecho, se afirma la siguiente secuencia causal: acción $\rightarrow$ sacrificio $\rightarrow$ lluvia $\rightarrow$ alimento $\rightarrow$ seres. Ahora bien, tal secuencia no es lineal sino circular, en la medida en que las acciones son realizadas por los seres, sobre todo si tenemos en cuenta, como afirma Sargeant, que en esta estrofa, el sentido del término karman es "acción religiosa", es decir, la acción ritual del sacerdote que realiza el sacrificio ${ }^{25}$. Concebido de este modo, el sacrificio es un paso constitutivo del ciclo cósmico y la renuncia a su realización pone en peligro la integridad del ciclo. La introducción de esta concepción en la Gìtāi implicaría una concesión al brahmanismo tradicional que sostiene la necesidad de la actividad ritual como la única garantía frente al caos (Van Buitenen, 1981, p. 16).

La segunda estrofa citada refuerza esta interpretación en la medida en que asevera que la acción tiene su origen en Brahman ${ }^{26}$. Tal afirmación nos alerta de que el término karman no debe comprenderse aquí como aludiendo a cualquier acción profana sino que debe restringirse su sentido al ámbito de la actividad ritual sagrada brahmánica. De hecho, numerosos intérpretes, comenzando por el célebre filósofo Sankara, comprenden que el término Brahman alude aquí a los Veda. Tola (2000), por ejemplo, vierte "Veda" mientras que en el sánscrito solo aparece brahman. Rollié (2017) traduce "fórmula ritual"; Sargeant (2009), "Brahman (the Vedas)"; y Van Buitenen (1981), "Brahman of the Veda", por mencionar algunos traductores. Si 
comprendemos que Brahman alude en este pasaje a los Veda, la relación entre karman y sacrificio se vuelve evidente, en la medida en que las acciones que prescribe el Veda son sagradas y rituales.

Como podemos apreciar, Kṛṇa condena el ritualismo védico en la medida en que esté movido por el deseo de goces y de poderío, pues produce apego y mantiene al ser humano en el ciclo de nacimientos y de muerte 27. Pero Kṛṣna también enseña que el sacrificio es necesario en términos cósmicos y, como la siguiente estrofa nos muestra, también en términos antropológicos, pues su realización trae beneficios espirituales.

Los que disfrutan el nectar (am $\mathrm{r}$ ta-bhujas) remanente del sacrificio van a Brahman, el eterno. Este mundo no es de los que no realizan el sacrificio. ¿Cómo (podría ser) el otro? oh, el mejor entre los Kuru ${ }^{28}$.

En una estrofa anterior ( $B h G$ III 13) ya aludida, Kṛșna afirma que quienes consumen los restos del sacrificio se liberan de todos los males, pero en este 's loka la afirmación es más fuerte pues se sostiene que la realización del sacrificio y el consumir los alimentos que quedan como fruto de este hacen que el hombre se dirija a Brahman.

En este punto de nuestro análisis, vale la pena aludir a una distinción propuesta por Upadhyaya. El autor afirma que si bien la Bhagavad Gìtā socava el valor del ritual, no lo rechaza en su totalidad. Los sacrificios condenados son los que se realizan sin ninguna clase de piedad interna y que son meras formalidades externas: serían sacrificios solo nominalmente (nämayajña) llevados a cabo con orgullo y por prestigio (XVI 17). Esta clase de sacrificios solo guían al sacrificador al infierno (XVI 16). Por el contrario, si los sacrificios son correctamente realizados, los dioses brindan a quien los realiza lo que él desea (III 12). En un tercer sentido, no obstante, "yajña" es utilizado para denotar el perfecto desapego basado en el conocimiento que es el mejor de todos los sacrificios. Esta tercera concepción sintetiza el sacrificio y el conocimiento y permite afirmar que las acciones que no sean sacrificios producirán un encadenamiento (III 9). Si tomamos estas tres distintas concepciones del sacrificio, afirma Upadhyaya, podemos apreciar que la primera de ellas implica rechazo del ritual, la segunda, desvalorización, y la tercera, aceptación: la primera conduce al infierno, la segunda al cielo y la tercera a la liberación (Upadhyaya, 1983, pp. 107-108). Esta distinción nos permite, asimismo, comprender mejor las siguientes estrofas.

Excepto por la acción cuya finalidad es el sacrificio (yajñārtha), este mundo está encadenado por la acción. Como alguien cuyo apego ha sido abandonado, oh hijo de Kunti, jrealiza la acción que posee esa finalidad! ${ }^{29}$

La acción de aquel cuyo apego se ha ido, del liberado, de aquel cuya mente está establecida en el conocimiento, del que actúa para el sacrificio, se disuelve enteramente ${ }^{30}$.

Estas dos estrofas introducen la noción de actuar para el sacrificio o de realizar una acción cuya finalidad es el sacrificio. Tal aclaración respecto de la acción ritual insiste en que la finalidad no sea algo diferente del sacrificio, como podría ser la satisfacción de los deseos y la ambición de poderío. Estas acciones, de hecho, encadenan, mientras que la acción cuya finalidad es el sacrificio (yajñārtha) no encadena. Esta acción, afirma la segunda estrofa, se disuelve ${ }^{31}$ y debe ser realizada. El uso del imperativo (samācara) en III 9 no deja lugar a dudas acerca de este punto de vista.

Ahora bien, en la segunda estrofa (IV 23) se introduce un nuevo elemento que no hemos discutido hasta ahora: la mente del que actúa de esta manera se encuentra establecida en el conocimiento (jñana). ¿Qué significa conocimiento en la Bhagavad Gìtā? Esta es otra temática que no podemos abordar exhaustivamente en el presente trabajo y que retomamos solo en función de nuestro análisis del sacrificio y del sí mismo ${ }^{32}$. Lo que debemos señalar es que, en numerosas estrofas, se establece una estrecha relación entre el sacrificio y el conocimiento, de manera que, el ritual sacrificial adquiere una nueva dimensión en virtud de esta relación. Podemos analizar esta nueva dimensión comenzando por la siguiente estrofa que ha causado cierta confusión entre los especialistas. 
Unos yoguis participan del sacrificio relativo a algún dios. Otros veneran el sacrificio con el sacrificio en el fuego que es Brahman $^{33}$.

Tola, por ejemplo, afirma que el sentido de estas líneas es oscuro (Tola, 2000, p. 78, nota 36), por lo que cabe preguntarnos cuál es el sentido de afirmar que se venera (upajubvati) el sacrificio (yajñam) con el sacrificio (yajñena) ${ }^{34}$. Una manera de comprender esta afirmación es considerar que el sacrificio se toma como objeto, como ofrenda del sacrificio mismo. Ahora bien, ¿cómo es posible que el acto de sacrificar sea, a la vez, ofrenda? Para que esta afirmación tenga sentido, parecería ser necesario operar un desdoblamiento en el sacrificio. Este desdoblamiento no opera en el plano de la acción sino del sentido. Habría, pues, un aspecto del sacrificio que es el de las acciones llevadas a cabo a partir de las que se constituye la dinámica y la performance del ritual. Podríamos denominar este aspecto como el sentido literal del sacrificio. Si alguien fuera a describir o relatar el sentido literal del sacrificio enumeraría la secuencia de acciones exteriores y visibles que este involucra. Pero debe haber otro plano para poder tomar al primer plano, el literal, como objeto u ofrenda de sacrificio. Este plano secundario, no sería ya literal sino metafórico, y no sería externo y visible, sino interno e invisible. Los yoguis a los que aludiría Kṛsna, pues, son los que ofrecen (jubvati) las acciones del ritual externo en el sacrificio entendido metafóricamente, interno. Tal concepción metafórica del sacrificio, como afirma Flood y Martin (2015), es central a la Gìtá ${ }^{35}$.

Parece necesario, entonces, reconstruir el sentido metafórico del sacrificio que estaría operando en la propuesta de Kṛnna. Este segundo sentido es el que se encuentra en estrecha relación con el conocimiento. Citemos algunas estrofas esclarecedoras en este sentido.

[1] Otros yoguis sacrifican todas las acciones de los sentidos y las acciones de los alientos en el fuego del yoga del control del sí mismo encendido por el conocimiento ${ }^{36}$.

[2] (Hay) otros, controlados, de votos firmes, cuyos sacrificios son los bienes materiales, cuyos sacrificios son las austeridades, cuyos sacrificios son el yoga y cuyos sacrificios son el conocimiento y el estudio ${ }^{37}$.

[3] Así pues, los sacrificios son de variadas clases, extendidos en la boca de Brahman. Conócelos a todos estos como nacidos de la acción. Tras conocer esto, tú serás liberado ${ }^{38}$.

[4] El sacrificio del conocimiento, oh destructor de los enemigos, es mejor que el sacrificio constituido por bienes materiales. Toda acción completa, oh Partha, está comprendida en el conocimiento ${ }^{39}$.

[5] Tal como el fuego encendido reduce los leños a cenizas, oh Arjuna, del mismo modo, el fuego del conocimiento reduce todas las acciones a cenizas ${ }^{40}$.

[6] Pues no existe aquí un medio de purificación semejante al conocimiento. El que se ha perfeccionado en el yoga lo descubre, él mismo, con el tiempo, en el sí mismo ${ }^{41}$.

Todas estas estrofas están incluidas en el capítulo IV, al que Malinar (2007, p. 94) divide en dos partes. La primera parte incluye, de acuerdo con la autora, las estrofas 1 a 14, versa sobre varios aspectos de la divinidad de Kṛṇa y posiblemente pertenece a una etapa de composición posterior ligada a lo que Ježíc denomina la síntesis bhakti ${ }^{42}$. La segunda parte comprende el resto del capítulo, describe prácticas ascéticas en términos de la acción ritual y se encuentra ligado por su contenido con el capítulo III. Ya mencionamos que Ježić (2009) incluye en la sección I (c) estrofas de ambos capítulos que versan acerca del sacrificio, entre las que encontramos estas últimas citadas, que evidencian una continuidad temática con otras estrofas también ya citadas del capítulo III.

Ahora bien, estas estrofas nos brindan un claro ejemplo de lo que varios autores han denominado "la interiorización del sacrificio". Flood (2004, pp. 65-66), por ejemplo, afirma que en los últimos siglos antes de la era cristiana, distintos problemas filosóficos relativos a la naturaleza del sí mismo, del mundo y de la acción comenzaron a ser desarrollados por el pensamiento brahmánico. Una concepción persistente se articuló en 
las Upanisad según la cual el conocimiento del sí mismo surge del desapego de la acción, especialmente de la acción ritual. Algunos brahmanes, afirma Flood, comenzaron a cuestionarse por qué realizaban sacrificios, concluyendo que el sentido profundo del sacrificio es su internalización, que es, a su vez, la realización de una sabiduría superior ${ }^{43}$.

Uno de los elementos clave de esta interiorización del sacrificio es, como afirma Heesterman (1993, p. 141 y siguientes), la internalización del fuego sacrificial. La Bhagavad Gìtä, en especial las estrofas citadas del capítulo IV, nos brinda testimonio de este fenómeno de interiorización del sacrificio y particularmente de la internalización del fuego sacrificial. La estrofa [1] muestra que se toma por objeto del sacrificio las acciones de los sentidos y de los alientos. En ella el fuego es identificado con el control del sí mismo, que es encendido por el conocimiento. La estrofa [2] toma por objeto de sacrificio los bienes materiales, el ascetismo, el yoga, el estudio y el conocimiento. La estrofa [4] establece la superioridad del sacrificio del conocimiento por sobre otro sacrificio, en la medida en que establece que todo otro sacrificio implica acción y que el conocimiento es superior a la acción. La estrofa [5] explica que la superioridad del conocimiento por sobre la acción se debe a que el conocimiento reduce a cenizas la acción. Todas estas estrofas utilizan la estructura del sacrificio, que implica colocar en el fuego una ofrenda con la finalidad de obtener un bien deseado, para explicar otra dinámica: la de la renuncia con la finalidad de obtener un bien deseado de un orden superior. Esta finalidad superior es la liberación, explicitada en la estrofa [3] como resultado del conocimiento de la unidad subyacente a la multiplicidad de sacrificios. Tal unidad consiste en que todos los sacrificios constituyen acciones ofrendadas a Brahman. Sin embargo, el procedimiento de interiorización del sacrificio y su asociación con la renuncia trae aparejada, a su vez, la internalización de la dinámica de la renuncia. Este segundo procedimiento de internalización permite a Kṛṣna conservar el ideal renunciante de las tradiciones śramanicas heterodoxas sin involucrarse con el abandono de la acción concreta y, por ende, con el desequilibrio que tal abandono implica para la sociedad tradicional brahmánica (Flood y Martin, 2015, p. $x v)^{44}$.

Olivelle (1993, pp. 104-105) explica con claridad que el problema central de la Gìtā, formulado al comienzo y que enmarca todo el diálogo entre Arjuna y Kṛna, se relaciona con la controversia entre los valores relativos a la acción (karman) y los valores relativos a la renuncia a la acción. Más allá del problema particular de Arjuna, el texto plantea el dilema que enfrentaron las personas de la época ante dos sistemas de valores contradictorios: el del dharma, interpretado como la obligación de realizar los rituales y las actividades sociales, y el de sa m nyāsa, entendido como el abandono de los ritos como precondición para alcanzar la liberación. De acuerdo con la respuesta que la Gìtā brinda a este dilema, la renuncia no consistiría en la abstención física de la actividad sino en la actitud mental apropiada en la realización de la acción. El abandono del deseo del resultado de la propia acción, afirma Olivelle, es la verdadera renuncia que la Gìtā concibe como una virtud interna más que como un modo de vida externo.

Ahora bien, la interiorización de la renuncia viene de la mano, como afirmamos, de la interiorización del sacrificio y del fuego sacrificial. Y en esta interiorización, el fuego sacrificial es identificado con el conocimiento, en tanto que es el conocimiento el que puede reducir toda acción a cenizas. El saber del que habla Kụṣna, no obstante, no es cualquier clase de conocimiento, como es de esperar, sino, como intentamos mostrar a continuación, el conocimiento del sí mismo.

\section{El sí mismo y SU Conocimiento en la BhagaVAd Gītā}

La estrofa [6] antes citada, treinta y ocho del capítulo cuarto, establece una estrecha relación entre el conocimiento y el sí mismo luego de haberse trazado una fuerte correspondencia entre el conocimiento y el fuego sacrificial. El conocimiento, de hecho, es caracterizado en [5] como el fuego que reduce toda acción a cenizas, y en [6] se afirma que este fuego purificador se encuentra en el sí mismo (ätman). Parece ser, pues, 
que el conocimiento del sí mismo es la llave maestra para que la purificación, la liberación y la renuncia interiorizada a la acción sean logradas.

El conocimiento del sí mismo, en términos generales, ha ocupado un lugar de gran importancia en la reflexión india desde el período de las Upanisad antiguas en adelante. Este aspecto de la producción intelectual india, por otra parte, ha despertado, en las últimas décadas, el interés de los estudiosos. Ganeri (2007, p. 1 y siguientes), por ejemplo, caracteriza el pensamiento indio acerca del sí mismo como una búsqueda por develar lo que se encuentra oculto. La verdad se encuentra cubierta, velada, y las metáforas de ocultamiento y los mitos de desocultamiento son de central importancia, afirma. Para los indios, agrega Ganeri, el ser al cual le ocurre tal ocultamiento es el sí mismo. A raíz de esto, el ser humano se encuentra en un estado de error auto-impuesto en relación consigo mismo, en tanto que las ideas que sostiene sobre esta noción central para su propia vida son equivocadas. Flood (2013, p. xii), por su parte, recurre a la noción de interioridad y sostiene que el pensamiento de la India acerca del sí mismo comparte con otras tradiciones una comprensión de la verdad interior entendida no tanto como una esfera privada sino como un imaginario común. Flood (2013, p. 2) reconoce el aspecto participativo de la interioridad pre-moderna y acuña el término "subjetividad compartida" (shared subjectivity) con la finalidad de mostrar que el sujeto de experiencias, el yo $(I)$, participa en una identidad más amplia. Subrayemos que Flood (2013, p. 5) sostiene que la interioridad de las sociedades pre-modernas ocurre vinculada intensamente con prácticas espirituales que buscan internalizar los textos de la tradición, por lo cual los textos son un elemento importante en un complejo de prácticas que constituyen la concepción y la experiencia de la interioridad.

Bronkhorst (2007, p. 37), por su parte, afirma que la Bhagavad Gìtā propone un método de intuición (insight) acerca de la verdadera naturaleza del sí mismo que coloca el énfasis en la actividad intelectual y distingue este método de otros de la época que demandaban inmovilidad física y mental. Afirma, asimismo, que el marco teórico de la Gìtā es cercano al sā ṃ khya, por lo cual se formula una concepción del sí mismo como diferente de la naturaleza corpórea y se propone que el hombre debe percatarse de esta diferencia. La cuestión que se plantea, de acuerdo con el autor (Bronkhorst, 2007, pp. 35-38), es cómo el aspecto material del ser humano, que incluye tanto su cuerpo como su mente, se comporta una vez que la diferencia mencionada ha sido puesta de manifiesto.

Interioricémonos, pues, en la concepción del sí mismo y de su conocimiento en la Bhagavad Gìtā tomando en cuenta el planteo de los autores citados. En línea con lo planteado por Bronkhorst, la primera discusión acerca del sí mismo la encontramos en el capítulo segundo, titulado sā ṃ khya-yoga. Allí, Kṛsna establece una distinción entre el cuerpo o deha y el ser encarnado o dehin ${ }^{45}$, y afirma del primero que es limitado y muere, mientras que el segundo es imperecedero, no nace y es inalterable ${ }^{46}$.

En este capítulo, se introduce la doctrina de la reencarnación, y se afirma que quien reencarna es este dehin que abandona unos cuerpos para tomar otros nuevos. Es interesante notar, asimismo, que la distinción entre un aspecto inmortal y otro mortal se afirma con claridad, aunque no se teoriza con precisión acerca del ser humano. De hecho, el término con el que se alude a quien reencarna es un derivado del vocablo "deha", cuerpo, por lo que el punto de referencia en la discusión es el cuerpo, respecto del cual se afirma que hay algo que lo posee (dehin), tal como un hombre posee y cambia sus vestimentas. La finalidad del capítulo parece radicar en establecer una contraposición que se propone de manera general y se aplica al ser humano en particular. Esta contraposición se establece a partir de dos binomios: por una parte, lo que es y la existencia (sat / bhavas) y, por otra, lo que no es y la inexistencia (asat / abhavas). Y como no es posible afirmar de lo que es que sea inexistente, a aquello que le corresponda el ser nunca le corresponderá la inexistencia.

Para lo que no es (asatas) no hay existencia (bhavas), para lo que es (satas) no hay inexistencia (abhavas). El límite (antas) entre ambos dos es visto por los que poseen la visión de la realidad (tattva $)^{47}$.

Resulta interesante la alusión a quien ve el límite infranqueable que separa lo que es de lo que no es en términos de tattvadar's i $n$ : el que posee la visión de tattva. Es cierto que el término tattva tiene un sentido 
genérico de "realidad" o "verdad", y así lo comprenden un gran número de traductores ${ }^{48}$. Pero en el contexto de una exposición que el texto mismo califica como $s \bar{a}$ mạ khya ${ }^{49}$, el término tattva puede ser tomado con un sentido más específico. Sin necesidad de entender que se alude a la doctrina clásica de los veinticinco tattva, es posible, no obstante, pensar que Kṛṣna alude a los que, mediante el tipo de razonamiento que él está aplicando en su exposición, establecen diferencias relevantes de corte ontológico ${ }^{50}$. Así pues, establecido este axioma de la imposibilidad de que lo que es posea inexistencia, se deduce que el individuo que pasa de un cuerpo a otro, como posee existencia, no puede dejar de ser.

Uno considera a este como un matador, y otro piensa a este como matado: ellos dos no comprenden, este no mata ni es matado.

No nace ni muere en ningún momento, ni, mucho menos, este, tras existir, será no existente. Él (es) no nacido, eterno, perpetuo, antiguo. Matado el cuerpo, no es matado ${ }^{51}$.

El hecho de que los términos ätman y puru $\mathrm{s}$ a no poseen aquí un sentido técnico abona nuestra interpretación de que la finalidad de este capítulo es distinguir clases de realidades y no teorizar acerca del ser humano. Ambos aparecen en esta sección por primera vez en el texto. El vocablo puru $\mathbf{s}$ a se introduce en la estrofa quince, donde se afirma que el puru $\mathbf{s}$ a que no es afligido por las sensaciones alcanza la inmortalidad. Debe comprenderse aquí una referencia genérica al hombre y no con un sentido equivalente al tattva del $s \bar{a}$ ṃ khya clásico, pues no tendría sentido afirmar que este alcanzaría la inmortalidad o que puede ser afligido por las sensaciones. El término vuelve a aparecer en la estrofa 60, en la que se alude al hombre (puru $\mathbf{s} a$ ) sabio cuya mente es atormentada por los sentidos.

En cuanto al término ätman, este aparece recién en la segunda mitad del capítulo, una vez que la exposición relativa al sā mạ khya (11-38) ha concluido y Kṛ̣na expone la sabiduría (buddhir, II 39) ${ }^{52}$ en el yoga (yoge) entre las estrofas 40-72. Aquí vale la pena recordar una distinción que traza Tola (2000, p. 51, nota 48) en relación con tres significados principales de átman: 1) el pronombre reflexivo: "uno mismo", "sí mismo"; 2) ser, esencia, naturaleza y 3 ) el espíritu, el yo verdadero en su aspecto más profundo, auténtico, trascendente. En el 's loka 43 Kṛșna alude a los que están compenetrados de deseos (kämātmānas) ${ }^{53}$, en el marco de su crítica al ritualismo védico. En esta estrofa, el término ātman correspondería al segundo sentido distinguido por Tola. En las estrofas 45, 55 y 64, en cambio, el término ätman posee un uso que correspondería al primero de los sentidos, el pronombre reflexivo. En estas estrofas Kụșna habla acerca del hombre que es dueño de sí mismo (ätmavān $)^{54}$, autocontrolado (vidheyātmā) mediante autocontroles (ätmava's sair) ${ }^{55}$, satisfecho por sí mismo en sí mismo (ätmanyevatmanà tu șt $a$ ḥ $)^{56}$.

\subsection{El locus classicus: BhG XIII}

El capítulo de la Bhagavad Gĩtā donde hallamos un examen de la concepción del sí mismo, el locus classicus como afirma White (1979, p. 501), es el decimotercero. De acuerdo con la división del texto en categorías textuales realizada por Ježić (2009), corresponde al estrato upanisádico, posterior al estrato textual épico pero anterior al devocional. En consonancia con lo señalado por Bronkhorst (2007, pp. 35-38), la noción del sí mismo es expuesta aquí en términos de la filosofía sā mạ khya. Pero esta exposición tiene en común con las Upanișad y con la épica que presenta una mayor fluidez terminológica que su versión clásica (Malinar, 2007, p. 192). También se distingue del sā ṃ khya de Íśvarakṛ̣na por su introducción de Kṛ̣ṇa (XIII 10, 18), de Brahman (XIII 12), de paramātman (XIII 31) y del gran señor (mahés vara, XIII 22) como componentes de la realidad. En el caso de Krșna, no obstante, Szcurek (2002, pp. 183-220) y otros estudiosos consideran que las tres estrofas del capítulo en las que se lo menciona (XIII 2,10,18) son interpolaciones correspondientes al estrato bhakti posterior. En cuanto a las otras nociones, ellas ponen en evidencia que estamos ante una síntesis del vedānta upanișadico y del proto-sā ṃ khya (White, 1979, p. 502). Malinar (2007, pp. 192-193) 
distingue acertadamente dos partes en el capítulo. En la primera de ellas se discuten los dos principios del $s \bar{a}$ makya en términos de "campo" $(k \mathbf{S}$ etra $)$ y "conocedor del campo" ( $k$ s etrajña $)$, mientras que en la segunda se utilizan los términos puru $\mathrm{s}$ a y prak $\mathrm{r} t i$, transición que responde a la fluidez terminológica antes aludida.

La primera de las dos partes mencionadas afirma que el campo es el cuerpo ('s arira, XIII 1) y que el que


analizado en función de su cuerpo: allí se distinguía entre el deha o 's arira y un debin / 's aririn, mientras que aquí la distinción es entre $k \mathrm{~S}$ etra y $k \mathrm{~s}$ etrajña. Esta nueva distinción, no obstante, se construye sobre la anterior, en la medida en que el $k \mathrm{~S}$ etra ahora señalado es el deha / 'sarīra introducido en el capítulo II, mientras que el $k \mathbf{S}$ etrajña sería el dehin. El énfasis en esta primera parte del capítulo XIII, por ende, está colocado en la capacidad de conocer del $k \mathbf{s}$ etrajña ("los que lo conocen llaman " $k \mathbf{s}$ etrajña" a aquel que conoce a este -al $k \mathrm{~s}$ etra-” $)^{57}$, mientras que en el capítulo II se hacía hincapié en que era eterno, imperecedero e incorruptible y no se hace alusión a su capacidad de conocer ${ }^{58}$.

Este conocimiento, por otra parte, no parece ser una capacidad que se actualiza y que en un primer momento no se ejercita, tal como es el conocimiento que un hombre adquiere a lo largo de su vida. El apelativo $k$ S etrajña, por el contrario, parece aludir al modo de relación, eterno e inmutable, que este posee con el campo / cuerpo, aunque la relación misma no sea eterna e inmutable, dado que la liberación es posible. Hay otro término que aparece en la estrofa 14 que, a nuestro entender, es paralela a esta: gu n abhokt r $o$ "disfrutador de los gu n $a$ ". Como es sabido, ambas nociones, bhokt ṛ y gu ṇ $a$, nos remiten al sā mạ khya. La primera es uno de los atributos que recibe puru $\mathrm{s}$ a y hace referencia a su capacidad de experimentador de prak $\mathrm{r} t i^{59}$. La segunda alude a una de las caracterizaciones más típicas de prak $\mathrm{r} t i$ : posee gu n a (sattva, rajas y tamas ${ }^{60}$.K $\mathbf{s}$ etrajña y gu n abhokt $\mathbf{r}$, pues, aluden a la relación de puru $\mathbf{s}$ a con prak $\mathrm{r} t i$, según la cual la segunda es, en términos amplios, objeto de conocimiento y disfrute del primero. Estas correspondencias nos permiten comprender que $k \underline{\mathrm{s}}$ etra y $k \mathrm{~S}$ etrajña son nociones paralelas a las de prak $\mathrm{r}$ ti y puru $\mathrm{S} a$, respectivamente, que se examinan en la segunda mitad del capítulo XIII.

Ahora bien, la primera sección del capítulo también evidencia una segunda concepción del conocimiento aparte de la implicada en el término $k \mathrm{~s}$ etrajña. Luego de enumerar los componentes del campo en las estrofas 5 a 11, Kṛṇa expone "lo que debe ser conocido" (jñeyam). En la estrofa 3, sin embargo, Kụsṇa ordena a Arjuna que escuche de él lo que le dirá acerca, por una parte, del campo y, por otra, acerca del conocedor del campo ${ }^{61}$, por lo cual la referencia a "lo que debe ser conocido" puede entenderse como aludiendo al kṣetrajña. Este último, además de ser conocedor del campo, es algo que debe ser conocido. Es evidente que hay dos concepciones diferentes de conocimiento involucradas aquí. Una implica el conocimiento atribuido al $k \mathrm{~S}$ etrajña. Tiene como objeto al campo y, en la medida en que este esté relacionado con el campo, el conocimiento es efectivo, es decir, no puede no darse. Se trata de una caracterización definitoria del puru $\mathrm{S}$ $a^{62}$. La otra concepción alude al conocimiento de lo que debe ser conocido (jñeyam), tiene como objeto al $k$ S etrajña y no siempre es efectivo, puesto que uno puede no conocerlo. Tal situación de desconocimiento es uno de los motivos por los que Kṛṇa brinda su enseñanza.

A partir de la estrofa 19 comienza la exposición en términos de puru $\mathrm{s}$ a y prak $\mathrm{r}$ ti. Citemos las estrofas más relevantes para nuestro análisis.

Sabe que prak $\mathrm{r}$ ti y puru $\mathbf{s}$ a son ambos sin comienzo. Sabe que tanto los efectos como los $g u$ n $a$ de $p r a k$ r $t i$ son originados por prak $\mathrm{r} t i{ }^{63}$.

El puru ș a que está en prak ṛ ti disfruta los gu ṇ a nacidos de prak ṛ ti. La causa de los nacimientos de este en matrices virtuosas o no virtuosas es el apego a los $g u$ n $a^{64}$.

El que conoce así a puru $\mathbf{s}$ a y a prak $\mathrm{r}$ ti junto a sus $g u$ n $a$, incluso existiendo en cualquier forma, ese no renace nuevamente ${ }^{65}$. 
Algunos, mediante la meditación en el sí mismo, ven al ātman por medio del ätman; otros, por medio del yoga propio del $s \bar{a}$ mạ khya, y aún otros por medio del yoga de la acción ${ }^{66}$.

Los que mediante el ojo del conocimiento conocen la diferencia entre el campo y el conocedor del campo, y la liberación respecto de la prak $\mathrm{r} t i$ de los seres (bhütaprak $\mathrm{r} t i)^{67}$, ellos se encaminan hacia lo supremo ${ }^{68}$.

A diferencia de lo que vimos en el capítulo segundo, en estas estrofas del capítulo trece el término puru $\mathbf{S}$ $a$ aparece con su sentido técnico. En consonancia con lo afirmado acerca del $k$ s etrajña (gu n abhokt ț, BhG

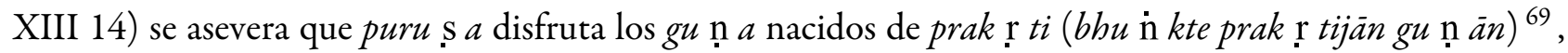
lo cual confirmaría que puru $\mathbf{s} a$ y $k \mathbf{s}$ etrajña son dos maneras diferentes de hacer referencia a lo mismo. La estrofa 23 , a su vez, alude a quien conoce al puru $\mathbf{s}$ a, conocimiento que correspondería a la segunda clase antes distinguida, el que tiene como objeto al $k \mathrm{~s}$ etrajña. Al distinguir las dos clases de conocimiento, también afirmamos que este segundo tipo podía no darse, lo cual es corroborado por la estrofa 23. Aquí se afirma que quien conoce a puru $\mathbf{s}$ a no renace nuevamente: es evidente que esto implica que hay quienes no lo conocen puesto que continúan renaciendo. Esta misma estrofa también aclara una diferencia crucial entre las dos modalidades de conocimiento: la primera, que posee al campo como objeto, le corresponde al $k \mathrm{~s}$ etrajña o puru $\mathbf{s} a$ entendido en su sentido más técnico, mientras que la segunda que tiene al puru $\mathbf{s} a$ en sentido técnico como objeto, le corresponde al hombre empírico ${ }^{70}$. A raíz de esto, cabe señalar otro contraste entre ambas clases de conocimiento: la primera parecería efectivizarse de la mano del estado de no liberación (dado que implica la asociación entre puru $\mathbf{s}$ a y prak $\mathrm{r}$ ti), mientras que la segunda, sería causa de la liberación.

La siguiente estrofa citada enumera algunos de los medios que permiten al ser humano ver al àtman. Es interesante notar que el término puru $\mathrm{s}$ a se deja aquí de lado y se prefiere este otro término, que si bien puede entenderse como haciendo referencia al mismo puru $\mathbf{S}$ a, subraya el hecho de que puru $\mathbf{S}$ $a$, en su sentido técnico, es el sí mismo -ätman- propio del ser humano ${ }^{71}$. En la primera sección de este capítulo, de hecho, se afirma que el $k$ S etrajña "está presente en el corazón de todos los seres" ${ }^{72}$, recurriendo a una caracterización upanisádica típica para hacer referencia al ātman ${ }^{73}$. Este uso del vocablo entendido como equivalente a purușa correspondería al tercer sentido de "ätman" de los distinguidos por Tola y mencionados anteriormente: "el espíritu, el yo verdadero en su aspecto más profundo, auténtico, trascendente", aunque, insistimos, conserva su sentido pronominal que subraya el hecho de que ese aspecto más profundo, "espiritual”, digamos, es el sí mismo (Tola, 2000, p. 51) ${ }^{74}$. Entre los medios para verlo se mencionan la meditación en el ätman (dhyānenätmani), el yoga de la acción (karmayogena) y el sā ṃ khyayoga (sā mạ khyena yogena $)^{75}$. Es interesante notar que esta enumeración retoma las enseñanzas ya expuestas en secciones anteriores de la Bhagavad Gìtā en los capítulos II (sā ṃ khya-yoga), IV-V (karma-yoga) y VI (dhyāna-yoga) pero no incluye ninguna referencia a Kṛnna ni a las enseñanzas relacionadas con la bhakti o devoción.

La última estrofa citada ( $B h G$ XIII 34) corrobora varias de las conclusiones de nuestro análisis. Por una parte, se afirma que se encaminan hacia lo supremo quienes conocen (vidur), pero dado que no todos se encaminan hacia lo supremo, no todos conocen; por lo tanto, el conocimiento al que se alude aquí es el que posee el ser encarnado que puede no darse en muchos casos. Este conocimiento, por otra parte, tiene por objeto al $k$ s etrajña o puru $\mathbf{s} a$, en la medida en que se afirma que aquellos conocen el límite o la diferencia (antara $\mathbf{m}$ ) entre $k \mathrm{~s}$ etra y el $k \mathrm{~s}$ etrajñ ${ }^{76}$. La estrofa agrega que aparte de la diferencia entre ambas realidades, aquellos conocen que prak $\mathrm{r} t i$ es algo respecto de lo cual es posible obtener la liberación $(m o k \mathrm{~s} a)$, retomando las terminologías de ambas secciones del capítulo. Finalmente, se introduce la expresión "mediante el ojo del conocimiento", que permite resignificar las distintas alusiones que el capítulo contiene a la visión (dar's ana, 11) y al o a los que ven (formas verbales de (anu)PAS en estrofas 24, 29, 30) en términos de la comprensión que se posee gracias al conocimiento discriminador (el de la segunda clase). Citemos una última estrofa: 
El puru ș a superior, cuando está en este cuerpo, es llamado contemplador y consentidor, sostenedor, disfrutador, gran señor, incluso, sí mismo supremo ${ }^{77}$.

Esta última estrofa resume varias de las nociones que hemos apreciado en el examen del capítulo XIII. El sujeto de la estrofa es puru $\mathrm{s} a$ h para ḥ, expresión que alude a lo que denominamos concepción técnica del puru $\mathbf{s} a$ en la medida en que no hace referencia al hombre (puru $\mathbf{S}$ a) empírico. Se predican de este puru $\mathbf{s} a$ varios adjetivos formulados como agentes en -tr: contemplador (upadra ștri), consentidor (anumant $\mathbf{r}$ ), sostenedor (bhart $\mathbf{r})$ y disfrutador (bhokt $\mathbf{r}$ ). La primera de las nociones es asimilable a la de $k \mathbf{s}$ etrajña, la última ya la habíamos comentado tanto respecto del $k \mathrm{~s}$ etrajña (estrofa 14) como de puru $\mathrm{S} a$ (estrofa 21). El término anumantṛ no aparece en todo el texto de la Bhagavad Gìtā excepto en esta instancia. Tola (2000, p. 171) traduce "que deja hacer" y en una nota al pie indica que este dejar hacer iría de la mano del hecho de que "la actividad de la materia manifestada bajo la forma de la vida psicológica (sentimientos, voliciones, etc.)" no lo afecta en absoluto ${ }^{78}$.

En la estrofa se afirma también que a aquel se lo llama "sí mismo supremo" (paramātmā), lo cual corrobora nuestra afirmación de que el término técnico puru $\mathbf{s}$ a debe ser concebido como el sí mismo del ser humano, pero, a la vez, como el sí mismo absoluto, que se diferencia del sentido del yo transitorio que posee el ser humano empírico. Finalmente, el término bhart ṛ, sostenedor, nos permite establecer una muy interesante conexión entre dos nociones.

\subsection{Purușa y Brahman}

Luego de la sección del capítulo XIII en que Kụsṇa explica qué es el campo (estrofas 5-11), se introduce la figura de Brahman a la cual se le dedican varias estrofas (12-17) que contienen paráfrasis e incluso citas textuales de las Upanișad ${ }^{79}$. De él se afirma que es "experimentador de los gu ṇ a" (gu ṇ a-bhokt r r) ${ }^{80}$ y "sostenedor de los seres" (bhüta-bhart $\mathbf{r})^{81}$, tal como se afirma del $k$ s etrajña / puru $\mathbf{s} a$. También se lo describe en términos de "lo que debe conocerse" (jñeyam) ${ }^{82}$, tal como habíamos señalado que se describía al $k$ s etrajña / puru $\mathrm{s}$ a. Esto nos encamina, como escribe White (1979, p. 503), a formularnos la siguiente pregunta: ¿debemos pensar al puru $\mathbf{S}$ a superior como equivalente al Brahman de las Upanisad? La respuesta de White a esta pregunta es "no". Sin embargo, White responde de esta manera dado que considera que la Gìtā expone una concepción no upanișadica de Brahman. El autor sostiene, acertadamente a nuestro entender, que en los primeros capítulos de la Gìtā Brahman es concebido como equivalente a prak $\mathbf{r} t i$. Pero a partir de su análisis de los capítulos VII y VIII, White entiende que la Gìtā posee una concepción de dos Brahman: uno superior, trascendente, que se identifica con Krṣna (y con un puru $\mathbf{s}$ a supremo) ${ }^{83}$, y otro inferior, inmanente, que se identifica con la prak r ti no diferenciada o pradhāna. Ahora bien, los capítulos a los que recurre White para establecer esta distinción corresponden a lo que Ježić (2009) identifica con el estrato bhakti, posterior al estrato upanisádico, si aceptamos su hipótesis de la composición del texto en diferentes etapas. Pero si limitamos nuestro análisis en el estrato upanisádico y hacemos a un lado los capítulos del estrato bhakti, cabe la pregunta de si en este estrato más antiguo es posible establecer una identidad entre Brahman, por un lado, y el puru $\mathbf{s}$ a superior y paramātman, por otro. Creemos, por nuestra parte, que sí, y la coincidencia terminológica señalada anteriormente con la que se describe a puru $\mathbf{s}$ a y a Brahman apunta en esta dirección. Ambos son concebidos como bhart r o sostenedores, como jñeyam o lo que debe ser conocido, y como bhokt r o disfrutador.

Otros elementos abonan la interpretación que entiende que Brabman es identificado con purusa en el estrato upanisádico. Nos limitamos a examinar dos. El primero de ellos es un aspecto de la concepción de los gu n $a$ característica del texto. Ya hemos mencionado que para el $s a ̄$ ṃ khya clásico prak $\mathbf{r} t i$ es trigúnica o posee tres gu n a: tamas, rajas y sattva ${ }^{84}$. La Bhagavad Gïtā, por el contrario, afirma en repetidas oportunidades 
que los gu n a a nacen de prak r $t i$, algo que no se afirma en el texto de T́svaraḳ̣ṣna ${ }^{85}$. Esto podría entenderse como aludiendo a que no toda o no siempre prak r ti sería trigúnica. Si nosotros interpretamos que el estado inmanifiesto de prak $r$ $t i$ es asimilado en el estrato upanisádico de la Gìtā tanto con Brahman como con puru $\mathrm{s} a$, esta lectura nos permite entender que la prak $\mathrm{r}$ ti no manifiesta carecería de los tres $g u$ n $a$ y que estos nacen en ella en su proceso de manifestación. Así pues, nuestra identificación de prak r $r$ ti no manifiesta con Brahman y con puru $\mathbf{s} a$ no implica considerar que estos son concebidos como poseyendo $g u$ n $\mathbf{a}$. Nuestra interpretación, por otra parte, es consistente con uno de los pocos trabajos dedicados al análisis de la concepción de los $g u$ ṇ a en Bhagavad Gìtā. Briggs Stansell (2008, pp. 61-80), su autora, sostiene que los gu ṇ a en la Gītā, más que cualidades de prak r $t i$-tal como son en el $s \bar{a}$ m khya clásico- serían cualidades de los seres encarnados: facultades cognitivas, características personales, afectos y comportamientos que los seres encarnados pueden poseer, exhibir o llevar a cabo. Tal manera de leer este aspecto de la obra, comenta Briggs Stansell, encuentra su voz tradicional en el comentario de Rāmānuja (s. XI), el Gītābhā s ya, y se opone a la lectura de Sankara (s. VIII), que proyecta sobre el texto la concepción clásica de los gu n a a pasando por alto sus particularidades.

Un segundo aspecto que contribuye a nuestra interpretación es una imagen que el texto desarrolla en su capítulo XV. Citemos las estrofas.

Dicen que el árbol aśvattha, cuya raíz está arriba y su ramaje abajo (y) cuyas hojas son los himnos (védicos), (es) imperecedero. Quien conoce esto es un conocedor del Veda.

Y sus ramas están extendidas hacia abajo (como si fuera) arriba, alimentadas por los guṇa y cuyos brotes son los objetos (de los sentidos); y las raíces están extendidas hacia abajo implicadas en las acciones en el mundo de los hombres.

Así, aquí su forma no es captada, ni el final, ni el comienzo ni tampoco su fundamento. Tras cortar este aśvattha, cuya raíz está bien crecida, con el hacha firme del desapego, debe buscarse entonces ese puesto, llegados al cual no regresan nuevamente. Ciertamente, yo tomo refugio en este primer purușa, a partir del cual la actividad antigua ha fluido (BhG XV 1-4).

Ya George Haas (1922, pp. 1-43), un siglo atrás, señaló los paralelismos entre este pasaje y algunas Upanisad $^{86}$. En la Ka tha Upani $\mathrm{s}$ ad, de hecho, encontramos la misma imagen de un árbol a's vattha invertido cuyas raíces se extienden hacia arriba y sus ramas hacia abajo. Es necesaria una aclaración previa, no obstante, respecto de este pasaje de la Gìtā. A partir de la segunda estrofa, se adopta el metro tri șt $u b h$, con lo cual la primera estrofa pertenecería, de acuerdo con Ježic (2009, pp. 215-282) a una etapa más temprana que las siguientes. Las estrofas dos a cinco corresponderían a lo que el autor identifica como un himno que se compuso de manera independiente y que se incorporó al texto de la Gìtā con anterioridad al estrato bhakti ${ }^{87}$ . Tomando lo anterior en cuenta, examinemos primero la estrofa cuatro. Allí se afirma que el primer puru $\mathrm{s} a$ es la fuente de la cual la actividad procede. Esto nos permite afirmar que no parece haber una discontinuidad entre puru $\mathrm{s}$ a y el ámbito donde la actividad se desarrolla. La imagen de la raíz del a 's vattha parecería ser adecuada a tal caracterización del puru $\mathbf{s}$ a. En la estrofa tres, por otra parte, se afirma que el puru $\mathbf{S} a$ aludido en la estrofa cuatro se alcanza tras cortar el árbol con el hacha del desapego. Esta metáfora refuerza la noción de continuidad entre el puru $\mathbf{S}$ a y el mundo, en la medida en que la liberación se alcanzaría separando mediante un proceso trabajoso lo que en un principio presenta una continuidad orgánica, digamos. La estrofa dos robustece la interpretación cósmica del árbol cuando se afirma que los brotes de las ramas, incrementadas por $\operatorname{los} g u$ ṇ $a$, son los objetos. Esta estrofa, a su vez, está en consonancia con la interpretación de los gu ṇ a que comentamos antes, en la medida en que no se afirma que los $g u$ n a están en la raíz o en todo el árbol sino que solo se hace referencia a los $g u$ n $a$ en relación con las ramas. En cuanto a la primera estrofa, que como dijimos es un 's loka, en apariencia al menos no concuerda con la interpretación cósmica del $a$ 's vattha, en la medida en que se comparan sus hojas con los himnos védicos. Sin embargo, podemos recordar que al citar la estrofa II 45, vimos que la $B h G$ afirma que los Vedas tienen por objeto lo que posee tres gu na $a$. Si tomamos en cuenta, asimismo, que en la imagen del $a$ 's vattha las ramas están alimentadas por los $g u$ n a y que las hojas que penden de las ramas son los himnos védicos, podemos comprender con claridad que la primera estrofa del capítulo XV no se contradice en absoluto con las siguientes estrofas: del árbol cuya raíz superior es puru 
$\mathbf{s}$ a-Brabman se desarrolla la totalidad del universo, incluso también el Veda. Cabe considerar, pues, que si el Veda pertenece a las ramas y estas deben ser cortadas con el hacha del conocimiento, quien ha alcanzado el conocimiento ya no tiene necesidad del ritual védico, tal como afirma Sutton (2016, p. 221). Tal idea se expresa en II 46, cuando Kṛsna afirma: "Para el brahmán que conoce, en todos los Veda hay tanto valor como en un pozo cuando el agua fluye por todas partes".

Reparemos, por último, en el carácter intertextual de este pasaje. La estrofa uno incluye un "dicen" (prähur) y posiblemente haga referencia a la $K a$ t ha Upani $\mathbf{s}$ ad, donde no solo encontramos la misma imagen del árbol invertido, sino que incluso utiliza las mismas expresiones. En ambos casos, se trata del mismo árbol, el $a$ 's vattha, y se afirma que las raíces están arriba (ürdhvamūla) mediante una expresión idéntica. También en ambos pasajes las ramas ('s $\mathbf{a} k h a$ ) están abajo, aunque en la $K a$ t $h a$ se utiliza el adverbio avāk mientras que la Gìtā usa adhas para indicar la dirección. En los dos pasajes, se alude a la eternidad del a 's vattha mediante los términos sanātana $\left(K a\right.$. tha) y avyaya $(G \bar{t} t \bar{a})^{88}$. Parecería, pues, que se trata de una cita textual y explícita. Llama la atención, asimismo, que en la Gìtā se afirma que quien conoce esto es un conocedor del Veda, y, haciendo a un lado el carácter simbólico del conocimiento aludido en esta imagen, también debemos tener en cuenta que al tratarse de una cita de la $K a$ t ha Upani sad, Kṛṣna está afirmando, en un sentido más literal, que quien entiende de qué está hablando es porque conoce la Upanisad. En un sentido más profundo, se podría entender que Kụṇa está otorgándole a ese pasaje de la $K a$ t ha que él cita un carácter paradigmático del conocimiento transmitido por el Veda, como si la imagen del árbol de la Upanisad poseyera una clave hermenéutica para comprender el sentido subyacente del Veda.

Ahora bien, completemos nuestro análisis de la estrofa upanisadica. Luego de describir al árbol, la $\mathrm{Ka}$ t ha añade "esto es resplandeciente, esto es Brahman, esto, ciertamente es llamado inmortal. Todos los mundos residen en esto, nadie puede ir más allá de esto” ( $K a$. t ha Up. VI 1). Como podemos apreciar, la $K a$ t ha identifica explícitamente al a's vattha con Brahman, como la totalidad continua que sostiene, da origen y nutre a todos los mundos. Dado que la Gìtā está introduciendo una cita textual de la $K a$. t $h a$, bien podemos entender que se está haciendo referencia a una determinada concepción de Brahman que implica una unidad y continuidad de todo lo existente, más allá de lo cual tampoco sería posible adentrarse. Todos estos elementos, pues, otorgan mayor sustento a nuestra interpretación de la identificación entre puru $\mathrm{s} a \mathrm{y}$ Brahman en las enseñanzas correspondientes al estrato upaniṣadico de la Gìtā y de la continuidad sustancial, por así decirlo, entre el puru $\mathrm{s} a$, Brahman y el mundo.

En fin, si aceptamos las hipótesis iniciales fundadas en la lectura estratificada del texto, no parecería posible interpretar que en la etapa upanișadica de la redacción de la Bhagavad Gìtā hay una concepción calificable como "dualismo sustancial". Tal visión no dualista, por otra parte, sería consistente con las descripciones del sāṃkhya preclásico que hallamos en otras obras más o menos contemporáneas a la Gìtāa ${ }^{89}$. El dualismo del sāṃkhya, por el contrario, es propio de su expresión clásica, tal como la encontramos en la Sā ṃ khya-kārikā de T'svarakṛșna, como es sabido. En la etapa upanișádica de la Gìtāa, pues, parecería que todavía permanece vigente la antigua imagen rg-védica según la cual el mundo, los dioses y el Veda tienen un mismo y único origen.

\section{Conclusión}

En el presente trabajo ofrecimos un análisis de la noción de sí mismo y de su conocimiento en la Bhagavad Gìtā y buscamos mostrar que el desarrollo de estas concepciones aparece en el texto de la mano de una interiorización del sacrificio. Comenzamos, no obstante, señalando las correspondencias que se establecen entre puru $\mathbf{s}$ a y el sacrificio ya en la literatura védica, tanto en los himnos como en las Upanisad antiguas. Vimos que en el puru $\mathbf{s} a$-sūktam el sacrificio del puru $\mathbf{s} a$ cósmico es presentado como un proceso primordial, que sitúa tanto al puru $\mathbf{s}$ a como al sacrificio en el origen del mundo tal como lo conocemos. En la Chāndogya 
Upani $\mathrm{s}$ ad vimos que se ofrece una identificación del ser humano con el sacrificio y que se establece una correspondencia entre los distintos aspectos de la vida humana y las diferentes fases del ritual. Señalamos, asimismo, que en este texto se introduce la figura de Kṛna, que aparece estrechamente vinculada con la formulación que pone en relación tal comprensión de la vida humana en función del sacrificio.

En la segunda parte, ofrecimos un análisis de la Bhagavad Gìtā fundado sobre la hipótesis de la composición estratificada del texto y nos acotamos al estrato upanisádico, del cual examinamos específicamente las secciones dedicadas al sacrificio y al sí mismo. Vimos, por una parte, que Kụsna realiza una crítica del ritual védico, aunque también reconoce su relevancia cósmica y su poder liberador. Para sostener tales apreciaciones divergentes, propusimos entender que Kṛṣna opera un desdoblamiento en la noción de sacrificio, a partir del cual habría un sentido literal externo que se corresponde con las acciones rituales y un sentido metafórico interno que se corresponde con la renuncia. Tal asimilación del ritual interiorizado con la renuncia implica, a su vez, una interiorización del acto mismo de renunciar y de su objeto, en la medida en que lo que se abandona no es la acción sacrificial externa y concreta sino el deseo del beneficio que ella produce y el apego por sus frutos. Sostuvimos, por otra parte, que la interiorización del ritual, que es la condición para la interiorización de la renuncia, identifica al fuego ritual con el conocimiento del sí mismo. El conocimiento de sí, pues, se presenta como la clave para que la acción pueda ser abandonada, pero en el sentido en que el abandono de la acción es posible y deseable para Kṛsna. La acción prescrita debe ser realizada, pero con un completo abandono del apego por sus frutos: solo así la acción no encadena a quien actúa.

Ahora bien, en nuestro análisis del conocimiento de sí, vimos que el texto presenta dos concepciones divergentes. Una de ellas es el conocimiento propio del $k \mathbf{S}$ etrajña que toma como objeto a prak $\mathrm{r} t i$. La otra es el propio del ser encarnado y toma como objeto al puru $\mathbf{s} a$. El segundo es un conocimiento discriminador y es el que posibilita la liberación. En la formulación de esta segunda clase de conocimiento, indicamos, a su vez, que el puru $\mathrm{s} a$ es caracterizado mediante una terminología equivalente a la utilizada para caracterizar a Brahman, lo cual nos condujo a proponer que en el estrato upanișadico la concepción de puru $\mathrm{s} a \mathrm{y}$ de Brahman son solidarias y que ambas pueden identificarse con el aspecto indeterminado de prak $\mathrm{r}$ ti. Señalamos, por último, dos elementos del texto que abonan esta interpretación: la concepción particular sobre los gu n a que encontramos en la Gità y la referencia textual a la $K a$. tha upani sad con su introducción de la imagen del $a$ 's vattha.

Podemos afirmar, finalmente, que el conocimiento de la solidaridad entre las concepciones del sí mismo, el àtman o puru $\mathrm{s} a$, Brahman y el sacrificio es fundamental en el camino de liberación. Y estas correspondencias se dan tanto en el nivel individual como en el nivel cósmico, tal como ya la antigua literatura védica formulaba con claridad. Kụṣ̣a, asimismo, expresa estas ideas en una célebre estrofa de la Gītā:

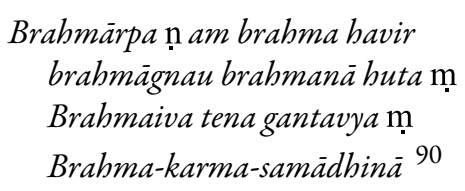

\section{Bibliografía}

Allen, M. S. (2014). Knowledge and Devotion in the Bhagavad-Gītā: A Suggestive Parallel from Chinese Buddhism. Dao, 13, 39-51.

Arnau, J. (2012). Cosmologías de la India. Védica, sāmkhya y budista. México: Fondo de Cultura Económica. Barnett, L. D. (1922). Hindu Gods and Heroes. Studies in the History of the Religion of India. Londres: John Murray. Briggs Stansell, E. (2008). The Guna Theory of the Bhagavad Gita. Journal of the Indian Council of Philosophical Research, 25(4), 61-80. 
Brockington, J. (1997). The Bhagavadgìtā: Text and Context. En J. Lipner (Ed.), The Fruits of Our Desiring (pp. 28-47). Calgary: Bayeux Arts.

Bronkhorst, J. (2007). Greater Magadha. Studies in the Culture of Early India. Leiden and Boston: Brill.

Bryant, E. (2014). Agency in Sāmkhya and Yoga. The unchangeability of the Eternal. En M. R. Dasti y E. F. Bryant (Eds.), Free Will, Agency, and Selfhood in Indian Philosophy (pp. 16-40). Oxford: Oxford University Press.

Cohen, S. (2018). The Upanisads. A Complete Guide. Londres y Nueva York: Routledge Taylor and Francis Group.

Dasgupta, S. (1957). A History of Indian Philosophy. (Vol. I). Cambridge: Cambridge University Press.

De Palma, D. (1992). Las Samkhya Karikas de Isvarakrsna. Estudios de Asia y África, 27(1), 171-191.

Devasthali, G. V. (1953). Bhagavadgītā and Upanisads. En J. N. Agrawal y B. D. Shastri (Eds.), Särupa-Bhāratī or the Homage of Indology Being the L. Sarup Memorial Volume (pp. 132-142). Hoshiarpur: Vishveshvaranand Institute Publications.

Feuerstein, G y Feuerstein, B. (2014). The Bhagavad-Gìtä. A New Translation. With the Sanskrit text, a Romanized transliteration, a word for word translation and extensive notes and supporting essays. Boston y Londres: Shambala.

Flood, G. (2004). The Ascetic Self. Subjectivity, Memory and Tradition. Cambridge: Cambridge University Press.

Flood, G. (2013). The Truth Within. A History of Inwardness in Christianity, Hinduism and Buddhism. Oxford: Oxford University Press.

Flood, G. y Martin, C. (2015). The Bhagavad Gìtā. New York: W. W. Norton \& Company.

Frazier, J. (Ed.). (2011). The Continuum Companion to Hindu Studies. New York: Continuum International Publishing Group.

Ganeri, J. (2007). The Concealed Art of The Soul. Theories of Self and Practices of Truth in Indian Ethics and Epistemology. Oxford: Oxford University Press.

Haas, G. C. O. (1922). Recurrent and Parallel Passages in the Principal Upanishads and the Bhagavadgitā with References to Other Sanskrit Texts. Journal of the American Oriental Society, 42, 1-43.

Heesterman, J. C. (1993). The Broken World of Sacrifice: An Essay in Ancient Indian Ritual. Chicago: University of Chicago Press.

Herrera, J. L. (2012). Las estrofas del Sāmkhya de Ishvarakrishna. Areté Revista de Filosofía, 24(2), 387-402.

Itzigueri Larios Robles, V. (2020). El cuerpo-cosmos: una interpretación del Purusasūkta. Konvergencias. Filosofias de la India, 10, 14-28.

Ježic', M. (2009). The Relationship Between the Bhagavadgitāa and the Vedic Upanisads: Parallels and Relative Chronology. En R. P. Goldman y M. Tokunaga (Eds.), Epic Undertakings (pp. 215-282). Delhi: Motilal Banarsidass Publishers.

Larson, G. J. (1998). Classical Sämkhya. An Interpretation of its History and Meaning. Delhi: Motilal Banarsidass Publishers.

Malinar, A. (2007). The Bhagavad Gìtā. Doctrines and contexts. Cambridge: CUP.

Monier Williams, M. A. (1899). Sanskrit-English Dictionary. Etimologically and Philologically Arranged. Delhi: Motilal Banarsidass.

Olivelle, P. (1993). The Áśrama System. The History and Hermeneutics of a Religious Institution. Oxford: Oxford University Press.

Olivelle, P. (1998). The Early Upanisads. Annotated text and translation by -. New York y Oxford: Oxford University Press.

Patil, G. M. (1960). Upanisadic References in Bhagavad Gītā. Annals of the Bhandarkar Oriental Research Institute, 41(1/4), 66-72.

Preciado-Solís, B. (1984). The Krsna Cycle in the Purānas: Themes and Motifs in a Heroic Saga. Delhi: Motilal Banarsidass.

Radhakrishnan, S. (1968). The Principal Upanisads. Edited with Introduction, text, translation and notes by -. London: Georg Allen \& Unwind LTD. 
Gabriel Martino. El sí mismo y su conocimiento en la Bhagavad Gī tā: La tradición sacrificial inter...

Radhakrishnan, S. (1970). The Bhagavad Gìtā. London: Georg Allen \& Unwind LTD.

Riviere, J. (1997). La Santa Upanishad de la Bhagavad Gita. Introducción, comentario y texto traducido del sánscrito de -. Buenos Aires: Kier.

Rollié, E. (2017). Bhagavad Gìtā. Buenos Aires: Colihue.

Sargeant, W. (2009). The Bhagavad Gìtā. Twenty-fifthe-Aniversary Edition. Translated by-. New York: State University of New York Press.

Sousa Silvestre, R. (2008). Philosophical Analysis and the Notion of Knowledge in the Bhagavad Gītā. REVER (PUC$S P), 4,114-148$.

Stansell, E. B. (2008). The Guna Theory of the Bhagavad Gita. Journal of Indian Council of Philosophical Research, 25(4), 61-80.

Sutton, N. (2016). Bhagavad-Gita. The Oxford Center for Hindu Studies Guide. Oxford: OCHS.

Szczurek, P. (2002). Some Remarks on the So-called Epic Layer of the Bhagavadgitā. En M. Brockington (Ed.), Stages and Transitions: Temporal and Historical Frameworks in Epic and Puranic Literature.Proceedings of the Second DICSEP, August 1999 (pp. 55-72). Zagreb: Croatian Academy of Sciences and Arts.

Szczurek, P. (2005). Bhakti Interpolations and Additions to the Bhagavadgitā. En P. Koskikallio. (Ed.), Epics, Khilas and Puranas: Continuities and Ruptures. Proceedings of the Third DICSEP, September 2002 (pp. 183-220). Zagreb: Croatian Academy of Sciences and Arts.

Tokunaga M. (s.f.). Bhagavadgita. Text based on the BORI edition of the Mahabharata on the basis of the text entered by - and revised by John Smith. Recuperado de http://gretil.sub.uni-goettingen.de/gretil/1_sanskr/2_epic/mb h/ext/bhgce_u.htm

Tola, F. (1968). Himnos del Rig Veda. Seleccionados y traducidos delsánscrito por Fernando Tola. Buenos Aires: Editorial Sudamericana.

Tola, F. (2000). El canto del Señor. Bhagavad-Gîtâ. Traducción y edición de Fernando Tola. Madrid: Biblioteca Nueva.

Tull, H. W. (1989). The Vedic Origins of Karma: Cosmos As Man in Ancient Indian Myth and Ritual. New York: State University of New York Press.

Upadhyaya, K. N. (1983). Early Buddhism and the Bhagavadgitāa. Delhi: Motilal Banarsidass.

Van Buitenen, J. A. B. (1959). Aksara. Journal of the American Oriental Society, 79(3), 176-187.

Van Buitenen, J. A. B. (1981). The Bhagavadgìtā in the Mahäbhārata. A Bilingual Edition. Translated and Edited by Van Buitenen. Chicago y Londres: The University of Chicago Press.

Villegas, L. (2016). İsvarakrsna. Sämkhyakārikā. Las estrofas del Sämkhya. Traducción, introducción y comentarios de Laila Villegas. Barcelona: Kairós.

White, D. (1979). Proto-Sāmkhya and Advaita Vedānta in the Bhagavadgitā. Philosophy East and West, 29(4), 501-507.

Zaehner, R. (1973). The Bhagavad Gita. With a commentary based on the original sources. Oxford: Oxford University Press.

\section{Notas}

1 Una versión preliminar de este trabajo fue presentada en una conferencia dictada en El Colegio de México en octubre de 2019. Agradezco al Dr. Adrián Muñoz y a los asistentes por sus observaciones y sugerencias.

2 En nuestro texto utilizamos el término "hombre" como traducción del término sánscrito "puruṣa", tratando de conservar, aunque imperfectamente, su amplitud semántica y, a la vez, sus connotaciones específicas.

3 Hay traducción al español de Tola (1968, p. 265 y siguientes).

4 Para un análisis más detallado del himno a puru ș a véase Tull (1989, p. 49 y siguientes) y Frazier (2011, p. 65). Véase también Itzigueri Larios Robles (2020, pp. 14-28), quien brinda un interesante análisis del himno con un foco puesto sobre la noción de corporalidad.

5 Chāndogya Upani ṣ ad III 16, 1. Para nuestras traducciones de la Chāndogya Upani ș ad seguimos el texto sánscrito establecido por Olivelle (1998). 
6 Chändogya Upani șad III 16, 2.

7 El metro gäyatrì tiene tres pies con ocho sílabas cada uno (24 sílabas en total). El metro tri șt $u b b$ tiene cuatro pies con once sílabas cada uno ( 44 sílabas en total). El jagati tiene cuatro pies con doce sílabas cada uno (48 sílabas). Compárese con Olivelle (1998, p. 545).

8 Chändogya Upani șad III 16,7.

9 Chändogya Upani șad III 17, 1-5.

10 Véase Radhakrishnan (1968, p. 396).

$11 \mathrm{La}$ Chändogya Upani șad es considerada una de las más antiguas, muy posiblemente prebudista y solo posterior a la $B \stackrel{\mathrm{r}}{\mathrm{r}}$ hadära n yaka Up. Los especialistas fechan su composición alrededor de los siglos VII y VI. a. C., compárese con Cohen (2018, p. 19).

12 Para una discusión detallada acerca de las diferentes posiciones y argumentos sobre la identidad o no de ambos Kṛṇa véase Preciado-Solís (1984, pp. 24-27).

13 Véanse, por ejemplo, Radhakrishnan (1970, p. 28 y siguientes) y Feuerstein y Feuerstein (2014, p. 22 y siguientes).

14 Seguimos el texto editado por Olivelle y, en cuanto al final de la frase, que es un tanto oscura, seguimos de cerca su traducción inglesa. Véase Olivelle (1998, p. 546).

15 Para una discusión detallada acerca de la relación entre la Bhagavad Gĩtā y las Upani șad medias como la Śvetaśvatara y la Katha Upani ṣa d véase Ježić (2009, pp. 215-282). La relación con la Gìtā y las Upani ṣad en general ha sido discutida y sus paralelismos han sido señalados por varias personas autoras. Véanse, por ejemplo, Haas (1922, pp. 1-43); Devasthali (1953, pp. 132-142) y Brockington (1997, pp. 28-47). Véase también Patil (1960, pp. 66-72).

16 Para una presentación de las investigaciones sobre Bhagavad Gìtā desde la perspectiva de la crítica textual, véase Szczurek (2002, pp. 55-72).

17 Comprende $B h G$ I; II 1-4; 9-10,31-37.

18 Comprende $B h G$ II 5-8; XI 15-50 y está compuesto en verso tri șt ubh (mientras que las otras secciones del texto están compuestas en śloka.

19 Las estrofas 13 a 15 y 17-18 del capítulo VIII pertenecerían a un momento anterior, de corte upanisádico. Véase, Ježić (2009, pp. 215-282). Para un análisis detallado de las interpolaciones de corte bhakti en el texto véase Szczurek (2005, pp. 183-220).

20 Véase, por ejemplo, Bryant (2014, pp. 16-40).

$21 B h G$ II $42-44$.

$22 B h G$ II 45. Para una discusión acerca de la noción de los gu n a en el sāṃkhya véase Arnau (2012, pp. 63-65). Para una discusión acerca de la concepción de los gu ṇ a en Bhagavad Gĩtä, véase, Briggs Stansell (2008, pp. 61-80).

23 Para un análisis de las estrofas III 12-13, véase Malinar (2007, p. 82 y siguientes).

$24 B h G$ III 14-15. Para un análisis más detallado de estas estrofas, véase Malinar (2007, p. 84 y siguientes) y Van Buitenen (1959, pp. 176-187).

25 Sargeant (2009, p. 171). Aún así, todo sacrificio entendido de manera amplia tiene su origen en la acción. Véase $B h G$ IV 32.

26 La estrofa 15 incluye el término "karman" simplemente, pero Van Buitenen (1981, p. 83), por ejemplo, traduce "ritual action”. Del mismo modo traduce Sargeant (2009, p. 172).

27 En XVII 12 Kṛṣna explica que esta clase de sacrificio es rajásico, en la medida en que es ofrecido con la mira en el fruto.

28 BhG IV 31. Compárese con XVI 23-24, donde Krṣna insiste de manera rotunda en que Arjuna cumpla con las prescripciones de los tratados tradicionales (śástravidhi), pues estos son el canon (pramā ṇa) que establece y distingue lo que debe hacerse (kärya) y lo que no debe hacerse (akärya). Ellos, además, permiten alcanzar la perfección (siddhi), la felicidad (sukha) y la meta suprema (parā m gatim). Véase, asimismo, XVIII 5-6.

$29 B h G$ III 9.

$30 B h G$ IV 23.

31 En $B h G$ XVII 11, Kṛșna explica que el sacrificio que se realiza sin deseo por el fruto, que se ofrece con vistas a las prescripciones tradicionales (vidhi) y pensando simplemente "ha de llevarse a cabo el sacrificio", ese es un sacrificio sattvico.

32 Para un análisis de la concepción del conocimiento en la Bhagavad Gĩtã véanse, por ejemplo, Sousa Silvestre (2008, pp. 114-148) y Allen (2014, pp. 39-51).

$33 B h G$ IV 25.

34 Monier Williams (1899, p. 1301) señala que cuando HU se construye con acusativo e instrumental significa "sacrificar a $(+$ ac. $)$ con (+ instr)" u "honrar a (+ ac.) con (+ instr)".

35 Flood y Martin (2015, p. xiv).

$36 B h G$ IV 27.

$37 B h G$ IV 28.

$38 B h G$ IV 32. 
$39 B h G$ IV 33.

$40 B h G$ IV 37.

$41 B h G$ IV 38.

42 Szczurek (2002, pp. 183-220) también considera las estrofas IV 1-15 como una interpolación bhakti.

43 Véase, asimismo, Heesterman (1993) quien realiza una distinción entre sacrificio y ritual apuntando, entre otras particularidades, a la progresiva internalización que caracteriza al segundo a diferencia del primero.

44 Véase, asimismo, la $B h G$ IV 21: "Aquel cuyo sí mismo ha controlado a la mente, Indiferente, cuyas posesiones todas han sido abandonadas, que realiza las acciones solo en cuanto al cuerpo, (ese) no comete error".

45 "Ser encarnado" traducen tanto Tola (2000) como Rollié (2017), aunque resulta más adecuada la traducción inglesa "embodied being". Compárese con Van Buitenen (1981). Tal vez podríamos traducir "el que posee un cuerpo".

46 Considérese, por ejemplo, las siguiente estrofa: “Así como, tras abandonar vestidos viejos, el hombre toma otros nuevos, de la misma manera, tras abandonar cuerpos (śarìrā $\mathrm{n} i$ ) viejos, el poseedor del cuerpo (dehin) se encuentra con otros nuevos" (BhG II 22).

$47 B h G$ II 16.

48 Tola (2000, p. 41): “verdad”; Sargeant (2009, p. 101): “truth”; Rollié (2017, p. 17): “verdad”; Flood y Martin (2015, p. 11): "truth", por mencionar unos pocos.

49 No solo en el título del capítulo sino también en la estrofa II 39, donde Kṛṣna afirma que ha expuesto la sabiduría (buddhi) de acuerdo con el sā mạ khya.

50 Nótese que Van Buitenen (1981, p. 75), por ejemplo, vierte “principles". Véase, asimismo, las estrofas III 28-29, donde el término tattva aparece en estrecha relación con una teoría de los gu ṇa.

51 II 19-20: ya enam vetti hantāram yaś cainaṃ manyate hatam / ubhau tau na vijānīto nāyạ̣ hanti na hanyate; na jāyate mriyate vā kadā cin; nāyaṃ bhūtvā bhavitā vā na bhūyạ̣ / ajo nityaḥ śáśvato 'yaṃ purāṇo; na hanyate hanyamāne śarīre.

52 El término buddhi adquiere en la filosofía sā mạ khya el sentido técnico de inteligencia, el primero de los tattva que se desarrollan a partir de prak r ti. En este pasaje, sin embargo, parece más adecuado comprender que se está haciendo referencia a una "doctrina” o "enseñanza”, dado que Kṛṣna ordena a Arjuna que la escuche (imām ś rụ $u$ ). Seguimos a Tola (2000, p. 45) en su elección de "sabiduría”. Compárese con Rollié (2017, p. 21), quien traduce "saber”.

53 La traducción "compenetrados de deseos" es de Tola (2000, p. 47). Se trata de un compuesto bahuvrīhi: "aquellos cuyo ätman es el deseo".

54 II 45.

55 II 64.

56 II 55.

$57 B h G$ XIII 1: etad yo vetti tam prāhuh kṣetrajña iti tadvidah.

58 En el capítulo II, de hecho, el sujeto del conocimiento de la diferencia entre el deha y el debin es el ser humano empírico, por así decirlo. Compárese con las estrofas II 21 y 29. El mismo que está confundido acerca de esta diferencia es quien debe comprenderla para eliminar esa confusión.

59 Véase $S a ̄$ ṃ khya-kärikā 17 y 37. Compárese con De Palma (1992, pp. 171-191) y Herrera (2012, pp. 387-402). Véase, asimismo, Villegas (2016).

60 La doctrina de los gu n a en Bhagavad Gìtā es otro de los interesantes aspectos del texto que no podemos examinar aquí y que, de acuerdo con algunos estudiosos, presenta importantes diferencias con la doctrina clásica de los gu ṇ $a$. Véase Stansell (2008).

61 En esta estrofa, la referencia al conocedor del campo se realiza mediante un pronombre relativo, no aparece el término $k$ s etrajña, pero la mayoría de los traductores reponen el término y, por ende, interpretan la estrofa de la misma manera que nosotros. Por ejemplo, Flood y Martin (2015, p. 65); Sargeant (2009, p. 531); Tola (2000, p. 166); Feuerstein y Feuerstein (2014, p. 253), entre otros. Van Buitenen (1981, p. 123 y siguientes) repone el término "guide", porque prefiere traducir $k$ s etrajña como "the guide to this field". Véase su nota 1 al capítulo XIII en la página 168.

$62 \mathrm{Al}$ menos del puru $\mathbf{s}$ a no liberado. Tal concepción justifica, por ejemplo, que Tśvarakṛṣna caracterice a puru ș a como jña (véase Sāṃkhya-kārikā 2).

$63 B h G$ XIII 19.

$64 B h G$ XIII 21.

$65 B h G$ XIII 23.

66 BhG XIII 24

67 El compuesto bhütaprak r $t i$ aparece también en la Cärakasa ṃ hitā I 63, donde se afirma que está compuesta por los cinco elementos, buddhi, avyakta y aha ṃ kāra. Véase Malinar (2007, p. 198, nota 208).

$68 B h G$ XIII 34.

69 Acerca de la afirmación de que los gu ṇ a son nacidos de prak ṛ ti (prak r tijān), véase Briggs Stansell (2008, pp. 61-80).

70 Téngase en cuenta que el hombre empírico también puede ser denominado purusa, en un sentido no técnico, como comentamos que ocurre en el capítulo II. Compárese, asimismo, $B h G \mathrm{XV} 16$, donde se afirma que hay dos puru $\mathrm{s} a$, 
uno perecedero y otro no perecedero: "todos los seres son el perecedero, el que está en la cima es llamado imperecedero". Nara y $p$ u m $s$ son otros términos que también aparecen en el texto para hacer referencia al hombre empírico. Acerca de la expresión kū t astha ("el que está en la cima"), véase Van Buitenen (1981, p. 168, nota 2).

71 White (1979, pp. 503 y 505) afirma enfáticamente que el capítulo XIII de la Bhagavad Gìtā concibe al puru ș a superior como equivalente al sí mismo supremo (paramātman) upaniṣádico.

$72 B h G$ XIII 17.

73 Véase Radhakrishnan (1970, p. 307). Se trata de una estrofa que ya contiene intensas resonancias upanișádicas. Véanse también Van Buitenen (1981, pp. 168-169) y Malinar (2007, pp. 195-196).

74 La noción de trascendencia, no obstante, resulta problemática en el contexto de la Bhagavad Gìtā. Van Buitenen (1981, p. 169) considera que en la estrofa 24 se yuxtaponen el uso reflexivo y el absoluto de àtman, los sentidos 1) y 3) de Tola (2000). El sentido absoluto, de acuerdo con Van Buitenen, sería el de la expresión "ven al ätman".

75 Rollié (2017, p. 131) traduce "a través del yoga del pensamiento"; Sargeant (2009, p. 552), “by the discipline of sā m khya”. Radhakrishnan (1970, p. 310) aclara que el término sā ṃ khya debe ser comprendido aquí como jñāna. Van Buitenen (1981, p. 169) traza una distinción entre el dhyāna-yoga entendido como un insight espontáneo ("without any propaedeusis") y el sā mạ khya, como un insight adquirido.

76 Afirmación paralela a la alusión al límite entre lo que no es y lo que es de la estrofa II 16.

77 XIII 22: upadraștānumantā ca bhartā bhoktā maheśvaraḥ / paramātmeti cāpy ukto dehe 'smin puruṣaḥ paraḥ.

78 Otros traductores interpretan el término de manera similar: "permitter" (Feuerstein y Feuerstein, 2014, p. 259); "consenter" (Sargeant, 2009, p. 550) y (Van Buitenen, 1981, p. 125).

79 Véase Zaehner (1973, p. 339 y siguientes).

$80 B h G$ XIII 14.

$81 B h G$ XIII 16. En $B h G$ XIII 14 se afirma que es sarvabh $\mathbf{r} t$, "sostenedor de todo".

$82 B h G$ XIII $16,17$.

83 puru șottama (BhG XV, 18).

84 Tanto lo inmanifiesto (avyakta) como lo manifiesto (vyakta), que son aspectos de prak r $t i$, son trigúnicos para el sā m khya clásico. Véanse las estrofas 11, 14, 17 y 18 de la $S a ̄$ ṃ khya-kārikà en Villegas (2016). Compárese con De Palma (1992, pp. 171-191) y Herrera (2012, pp. 387-402). Véase, asimismo, Villegas (2016).

85 Véanse III 5, XIII 21 y XVIII 40.

86 El autor señala la $K a$ t ha Up. VI 1; Śvet. Up III 9 y VI 6; Maitrī VI 15. Ježíc (2009, pp. 215-282) también señala el paralelismo con la R gueda-sa m hitā I 24, 7-8. Sutton (2016, p. 221) añade Muṇdaka 2.2.11.

87 Algunos autores afirman que las estrofas en metro tri ș $u b h$ deforman la imagen inicial, en la medida en que no mantienen la inversión del árbol. Véase, por ejemplo, Van Buitenen (1981, p. 169). Feuerstein y Feuerstein (2014, p. 273), por el contrario, aluden a una característica peculiar del árbol que permitiría leer de manera consistente todo el grupo de estrofas.

88 Subrayamos los términos idénticos y ponemos en cursiva las expresiones análogas.

ūrdhvamūlo avākśākha eșo 'śvatthah sanātanah / $/$ ūrdhvamūlam adhahśsākham aśvattham prāhur avyayam tad eva śukrạ̣ tad brahma tad evāmṛtam ucyate / chandāminsi yasya parnāni yastạ̣ veda sa vedavit tasmiṃl lokāḥ śritāḥ sarve tad u nātyeti kaścana chandāmsi XV 1 . Katha Up. VI 1.

89 Véanse, por ejemplo, Dasgupta (1957, p. 213 y siguientes) y Larson (1998, cap. II).

$90 B h G$ IV 24: "El ofrecimiento es Brahman, lo sacrificado es Brahman que por medio de Brahman es sacrificado en el fuego que es Brahman. Ciertamente, Brahman ha de ser alcanzado por aquel que medita en la acción ritual como Brahman”. 